\title{
Potential relations between extraversion and cardiovascular reactivity during laboratory stressors
}

Brandie K. Taylor

West Virginia University

Follow this and additional works at: https://researchrepository.wvu.edu/etd

\section{Recommended Citation}

Taylor, Brandie K., "Potential relations between extraversion and cardiovascular reactivity during laboratory stressors" (2001). Graduate Theses, Dissertations, and Problem Reports. 812.

https://researchrepository.wvu.edu/etd/812

This Thesis is protected by copyright and/or related rights. It has been brought to you by the The Research Repository @ WVU with permission from the rights-holder(s). You are free to use this Thesis in any way that is permitted by the copyright and related rights legislation that applies to your use. For other uses you must obtain permission from the rights-holder(s) directly, unless additional rights are indicated by a Creative Commons license in the record and/ or on the work itself. This Thesis has been accepted for inclusion in WVU Graduate Theses, Dissertations, and Problem Reports collection by an authorized administrator of The Research Repository @ WVU. For more information, please contact researchrepository@mail.wvu.edu. 
Potential Relations Between Extraversion and Cardiovascular Reactivity During Laboratory Stressors

\begin{abstract}
Brandie K. Taylor
Thesis submitted to the College of Arts and Sciences at West Virginia University in partial fulfillment of the requirements for the degree of
\end{abstract}

\author{
Master of Arts \\ in \\ Psychology
}

Kevin T. Larkin, Ph.D., Chair

Stanley H. Cohen, Ph.D.

Lindsey L. Cohen, Ph.D.

Department of Psychology

Morgantown, West Virginia 2001

Keywords: Cardiovascular Reactivity, Extraversion, Heart Rate, Blood Pressure Copyright 2001 Brandie K. Taylor 


\begin{abstract}
Potential Relations Between Extraversion and

Cardiovascular Reactivity During Laboratory Stressors
\end{abstract}

Brandie K. Taylor

This present study was designed to examine the relation between cardiovascular reactivity to stress and the behaviors of individuals classified as either "extraverts" or "introverts." Although experimental psychophysiological studies have been conducted to examine the relation between extraversion and physiological arousal, little is known about the ways in which extraversion and cardiovascular reactivity to stress are related. According to the optimal arousal theory, both extraverts and introverts would be expected to be more reactive to a social challenge than to a mundane non-social task, with introverts exhibiting greater reactivity to both tasks than extraverts. In contrast, a preferred task model would hypothesize that extraverts would be more reactive during a non-social task than introverts and that introverts would be more reactive than extraverts during a social task. In this study, 32 extraverted male and female undergraduates and 32 introverted male and female undergraduates participated in a social and a non-social task. Heart rate and blood pressure measures, as well as measures of self reported arousal, were obtained during both tasks and intervening rest periods. Results were unable to confirm either model as being predictive of the relation between extraversion and cardiovascular reactivity to mental stress. Females were found to exhibit lower resting systolic blood pressure than males, but no other gender differences were observed. Main effects for task were found, indicating that the social task was more arousing than the non-social task, which was further confirmed by the participants' self-reported levels of distress. Given the overall lack of results of the present and previous studies, further investigations would be better to focus more broadly upon established personality factors that may be contributing to cardiovascular reactivity, as well as to other lifestyle factors related to the development of cardiovascular disease. 


\section{Dedication}

I wish to dedicate this work to my great-grandfather, Andrew Harrison Warren, who passed away on Sunday afternoon, November 4, 2001. Grandpa, thank you for your never-ending supply of unconditional love! You have been one of the few people in my life to grant that precious gift to me - for that reason and many others, you will always hold a special place in my heart. I will forever love and cherish all of my memories of you.

Love always,

"Whiskey"

I would also like to dedicate this to my aunt, Jo Ellen Taylor, who passed away on Monday morning, November 19, 2001. To my Aunt Jo Ellen, who had the unrestricted innocence and love of a child, I will miss your smile!

Love always,

Brandie 


\section{Acknowledgments}

There are a number of people whom I would like to acknowledge as providing me with support throughout the various phases of this project. First, I would like to thank my advisor and thesis chairperson, Kevin Larkin, for his always prompt responses to my not-so-prompt inquiries, as well as for his never-ending words of wisdom. My appreciation also goes out to Stan Cohen and Lindsey Cohen for their patience, flexibility, understanding, and overall unequivocal contributions as members of my thesis committee.

I would also like to extend special thanks to Nicole Siegwarth for her help during the initial data collection phase of this project. Special thanks as well to Jeff Goodie, who always strived to help me whenever he could.

I am especially grateful for the support of Marvin Bumgardner and Jeannie Sperry who have often provided me with strength and support throughout this entire process.

Finally, I must express my appreciation to the West Virginia University Department of Psychology Alumni Fund for the financial assistance that was provided for this project. 
Table of Contents

Title Page

ABSTRACT

i

Dedication

ii

Acknowledgments

iii

Table of Contents

iv

List of Figures

List of Tables

Table of Appendices

INTRODUCTION

\section{v}

vii

viii

ix

1

Cardiovascular Reactivity to Stress and Its Relation to Cardiovascular Disease 3

Predictors of Cardiovascular Reactivity to Stress 4

Extraversion as a Predictor of Cardiovascular Reactivity to Stress 7

Gender as a Predictor of Cardiovascular Reactivity to Stress 9

STATEMENT OF PURPOSE $\quad 9$

$\begin{array}{ll}\text { METHOD } & 10\end{array}$

$\begin{array}{ll}\text { Screening Phase } & 10\end{array}$

$\begin{array}{ll}\text { Participants } & 10\end{array}$

$\begin{array}{ll}\text { Measures } & 10\end{array}$

$\begin{array}{ll}\text { Procedures } & 12\end{array}$

$\begin{array}{ll}\text { Laboratory Phase } & 13\end{array}$

Participants 13

Measures 13

Physiological Measures and Apparatus 14

Experimental Tasks 14

$\begin{array}{ll}\text { Procedure } & 15\end{array}$ 
RESULTS

Measures of Extraversion $\quad 16$

$\begin{array}{ll}\text { Subject Characteristics } & 17\end{array}$

$\begin{array}{ll}\text { Data Reduction } & 18\end{array}$

Resting Cardiovascular and Self-Report Measures $\quad 19$

Measures of Cardiovascular Reactivity 19

Self-Reported Measures of Distress 20

DISCUSSION

Behavioral Characteristics Associated with Cardiovascular Reactivity 21

Gender Differences in Cardiovascular Reactivity 24

Relation of Laboratory Tasks to CV Reactivity and Levels of Distress 26

$\begin{array}{ll}\text { Limitations of the Study } & 27\end{array}$

Directions for Future Research $\quad 28$

$\begin{array}{ll}\text { REFERENCES } & 30\end{array}$

\begin{tabular}{l|ll} 
TABLES & 35
\end{tabular}

$\begin{array}{ll}\text { APPENDICES } & 44\end{array}$

Curriculum Vitae $\quad 53$ 


\section{List of Figures}

Figure 1. Hypothetical Relation According to the Optimal Arousal Theory 8

Figure 2. Hypothetical Relation According to the Preferred Task Model 


\section{List of Tables}

Table 1. Means (and Standard Deviations) for Male and Female Extraverts and Introverts by Extraversion Measure 35

Table 2. Parametric Characteristics of Extraverts as a Function of Gender 36

Table 3. Parametric Characteristics of Introverts as a Function of Gender 37

Table 4. Non-Parametric Characteristics as a Function of Gender and Extraversion Classification

Table 5. Mean Heart Rates (bpm) (and Standard Deviations) by Gender and Extraversion Classification

Table 6. Mean Systolic Blood Pressures (mm Hg) (and Standard Deviations) by Gender and Extraversion Classification

Table 7. Mean Diastolic Blood Pressures (mm Hg) (and Standard Deviations) by Gender and Extraversion Classification

Table 8. Mean SUDS Ratings (and Standard Deviations) by Gender and Extraversion Classification

Table 9. Means (and Standard Deviations) of Cardiovascular Reactivity Measures Across Tasks and Studies 
Table of Appendices

Appendix A Demographics Questionnaire $\quad 44$

Appendix B Eysenck Personality Inventory 46

$\begin{array}{lll}\text { Appendix C SUDS Rating Scale } & 48\end{array}$

Appendix D ANCOVA Summary Table: Heart Rate Adjusted by Pre-Task Rest

Period Heart Rate 49

Appendix E ANCOVA Summary Table: Systolic Blood Pressure Adjusted by

Pre-Task Rest Period Systolic Blood Pressure $\quad 50$

Appendix F ANCOVA Summary Table: Diastolic Blood Pressure Adjusted by Pre-Task Rest Period Diastolic Blood Pressure 51

Appendix G ANCOVA Summary Table: Subjective Units of Distress Ratings Adjusted by Pre-Task Rest Period Subjective Units of Distress Ratings 52 


\section{Potential Relations Between Extraversion and Cardiovascular Reactivity During Laboratory Stressors}

For nearly a century, cardiovascular disease (e.g., coronary heart disease (CHD), stroke, hypertension, myocardial infarction, atherosclerosis) has been accredited as the primary cause of death in the United States (American Heart Association, 1997). Moreover, cardiovascular disease remains one of the leading causes of death in other industrialized nations (American Heart Association). Epidemiological studies have also purported that as many as one in five individuals suffer from one form or another of cardiovascular disease (American Heart Association). Given these statistics, cardiovascular disease constitutes an important area of study that may ultimately lead to a more complete understanding of the disease, as well as the development of effective intervention and prevention strategies that curb the deleterious effects of this disease.

Coronary heart disease and other cardiovascular diseases are progressive diseases that develop slowly over time. For instance, coronary heart disease develops as a result of the gradual build-up of plaques on the endothelial lining of the arteries. Plaques often begin to form on the interior walls of the arteries after the lining has been damaged due to high blood flow turbulence, which tend to occur particularly in areas of the arteries that are closest to the heart. The formation of such plaques may then lead to potentially serious atherosclerosis. Atherosclerosis occurs when plaque build-up begins to block the artery and eventually the flow of blood to the heart and/or to the brain, resulting in either a myocardial infarction or a stroke. Furthermore, chronically elevated blood pressure accelerates the damage to the lining of arteries that begins this entire process of plaque formation.

In fact, hypertension, or chronically elevated blood pressure of >140 $\mathrm{mm} \mathrm{Hg}$ for systolic blood pressure (SBP) and/or >90 mm Hg for diastolic blood pressure (DBP), is the single best predictor of the development of cardiovascular disease (Kannel, 1996). Exhibiting hypertension increases an individual's relative risk of developing coronary heart disease by 2 or 3 times that of an individual who does not exhibit hypertension (Kannel). Thus, hypertension has been demonstrated as being yet another risk factor for the development of coronary heart disease and 
other cardiovascular diseases, as well as a risk factor for cardiovascular disease-related mortality (Kannel).

The three leading risk factors for the development of cardiovascular disease include hypertension, in addition to serum cholesterol levels and smoking (Jenkins, 1988). However, these three factors only account for approximately $50 \%$ of the variance in the prediction of the development of coronary heart disease (Jenkins). Thus, the development of coronary heart disease and other cardiovascular diseases must also be attributable to other risk factors.

In fact, there are a number of other known risk factors for the development of cardiovascular diseases. Genetic or inheritable variables, such as the propensity for the development of diabetes, as well as age, are a few examples of predetermined and uncontrollable risk factors (American Heart Association, 1997). On the other hand, there are also a number of risk factors that are attributable to an individual's lifestyle and are therefore modifiable. These factors include two of the three leading risk factors for the development of cardiovascular disease: serum cholesterol levels and smoking (American Heart Association; Jenkins, 1988). Other modifiable risk factors include obesity and physical inactivity or sedentary lifestyle (American Heart Association).

Given that these factors only tend to account for about half of the variance in the prediction of cardiovascular disease, behavior patterns have also been examined as potential risk factors. Measures of hostility and time urgency (e.g., Barefoot, Larsen, Von der Leith, \& Schroll, 1995; King, 1997; Matthews \& Haynes, 1986) and anger experience (e.g., Siegel, 1984) (i.e., components of Type A behavior patterns), as well as depression (e.g., Booth-Kewley \& Friedman, 1987; Frasure-Smith, Lesperance, \& Talajic, 1993), represent behavior patterns that are reflective of individuals with greater risk for cardiovascular disease. Furthermore, a lack of social support may also influence the development and effects of cardiovascular disease on an individual (e.g., Orth-Gomer, 1994; Ruberman, Weinblatt, Goldberg, \& Chaudhary, 1984). 
Physiological reactions to stress have also been indicated as potential risk factors for cardiovascular disease. This relation has been extensively examined in the literature (Allan \& Scheidt, 1996), due in part to the findings that different individuals exhibit different physiological responses to different types of stress (Lacey, Bateman, \& Van Lehn, 1953; Moos \& Engel, 1962). Such studies have also indicated that while physiological responding to different stressors may differ between individuals, there tends to be a consistent pattern of responding within an individual to a variety of stressors (Andreassi, 1995; Lacey, Bateman, \& Van Lehn). Hence, while some individuals may exhibit a minimal physiological reaction to a particular stressor, others may show an inflated reaction to that very same stressor. In 1950, Malmo and colleagues postulated that such physiological reactions to stressors may indeed be related to disease processes.

\section{Cardiovascular Reactivity to Stress and Its Relation to Cardiovascular Disease}

This notion of individual physiological response specificity and its relation to disease processes can be directly applied to the study of cardiovascular reactivity to stress. Studies have shown that while some individuals do show minimal cardiovascular reactions to stressors (i.e., engaging, aversive, and/or challenging stimuli), others will exhibit inflated cardiovascular responses to the same stressor (Manuck, 1994). Combining such information with what Malmo et al. (1950) has postulated regarding the association between physiological responses to stressors and disease processes, researchers have developed what is known as the "cardiovascular reactivity" hypothesis (Krantz \& Manuck, 1984; Manuck, Kasprowicz, Monroe, Larkin, \& Kaplan, 1989). This hypothesis speculates that those individuals who characteristically exhibit inflated cardiovascular reactivity to stressful stimuli are more likely to develop cardiovascular disease than those individuals who characteristically exhibit lower and/or minimal levels of reactivity to the exact same stressor (Manuck; Manuck et al.).

Support for the cardiovascular reactivity hypothesis had been demonstrated in a number of studies. Animal studies with cynomolgus monkeys (Manuck, Kaplan, \& Clarkson, 1983; Manuck, Kaplan, Adams, \& Clarkson, 1989) have demonstrated greater levels of atherosclerosis in both male and female monkeys who exhibited higher levels of cardiovascular reactivity in 
response to stress (i.e., threat of capture). Similar results have been found with human subjects in case-control studies (e.g., Corse, Manuck, Cantwell, Giordani, \& Matthews, 1982; Hastrup, Lights, \& Obrist, 1982; Hollenberg, Williams, \& Adams, 1981). Moreover, prospective studies (e.g., Barnett, Hines, Schirger, \& Gage, 1963; Barnett, Spence, Manuck, \& Jennings, 1997; Keys et al., 1971; Menkes, et al., 1989) examining cardiovascular reactivity to laboratory and/or psychological stressors and the development of cardiovascular disease have again demonstrated a relation between high reactivity to stress and the development of disease.

\section{Predictors of Cardiovascular Reactivity to Stress}

Given the relation between cardiovascular response to stress and risk for cardiovascular disease, determining which individuals are more likely to exhibit higher levels of reactivity, and thus increased risk of disease, was the next logical step in this line of research. Researchers have taken this approach via a number of different avenues. One such avenue has been to examine individual characteristics or behavioral traits of individuals that are related to the magnitude of behaviorally-elicited cardiovascular responses.

Studies have demonstrated that a number of behavioral traits or characteristics are associated with greater levels of cardiovascular reactivity to stress. Characteristics such as hostility (e.g., Dembroski, MacDougall, \& Lushene, 1979), self-reported anger (e.g., Glass, Lake, Contrada, Kehoe, \& Erlanger, 1983), anger experience (e.g., Siegel, 1984), and "the coronaryprone behavior pattern" (i.e., a syndrome of traits and behaviors including competitiveness, achievement-orientation, aggressiveness, and impatience) (cited in Jenkins, 1971), have each been found to be associated with cardiovascular reactivity to stress as well as to the development of cardiovascular disease.

While these behavioral traits have had numerous studies devoted to them, other behavioral characteristics, such as extraversion, have received little, if any, attention in the literature. The disregard of the dimension of extraversion in the literature is confusing given its sound basis in biological theory. Eysenck (1967) postulated that individuals differed in their levels of extraversion based on variations in reticular activation system activity, which is the part 
of the brain that maintains cortical arousal in response to external stimuli. Eysenck proposed that extraverts preferred to engage in a wide range of social activities because they were cortically underaroused (i.e., extraverts required more intense external stimulation than introverts in order to maintain an optimal level of cortical arousal, whereas introverts required very little external stimulation in order to maintain their optimal level of cortical arousal). Therefore, extraverts were often characterized as being more outgoing, uninhibited, impulsive, and social; introverts, however, were more often characterized as being withdrawn, quiet, introspective, inhibited, cautious, reserved, and non-social.

Based on Eysenck's (1967) theory, a number of psychophysiological studies have been conducted to examine the relation between extraversion and arousal via measures of EEG arousal as well as cardiovascular reactivity measures of arousal. In a review of more than a dozen studies of EEG arousal, Gale (1973) found conflicting results regarding the arousal levels of introverts versus extraverts. Introverts showed higher arousal levels than extraverts except when in either very interesting situations or when in excruciatingly boring situations (e.g., sitting quietly). In these specific situations, extraverts exhibited higher levels of arousal than did introverts. Gale suggested that these contradictory results might have been due to the types of tasks in which the individuals were engaged. Overall, these findings confirmed that introverts exhibited more cortical arousal than extraverts in most situations. However, when external stimulation was optimized (i.e., very interesting situations), extraverts exhibited more cortical arousal than did their introverted counterparts. In contrast, when external stimulation was devoid of interest (i.e., boring task), extroverts may have been engaged in self-stimulatory activities (e.g., fidgeting) in order to increase their arousal levels or they may have also become so stressed during such a boring task as to become paradoxically overaroused, thus exhibiting higher cortical arousal levels than introverts.

Specific examinations of the relation between extraversion and cardiovascular reactivity to stress have also demonstrated contradictory findings among the few studies limited to this explicit arena of research. In 1983, Glass and colleagues found no relation between extraversion and cardiovascular reactions. Fifty-six male participants were classified as either introverts or 
extraverts as based upon their scores on the 16 PF (16 Personality Factor) inventory. When exposed to laboratory stressors (i.e., mental arithmetic and a modified Stroop task), participants did not exhibit any differences in heart rate or blood pressure reactivity in accordance with their extraversion status. Thus, while this study utilized a different measure of extraversion than previous investigations, no significant differences were found among participants regarding the relation between extraversion and cardiovascular reactivity. These results suggested that individuals' reactivity responses did not differ on the basis of their extraversion status.

In contrast to the previous findings, Geen (1984) found that male extraverts and introverts exhibited different cardiovascular reactivity in response to differential stimuli. A total of 60 males subjects, classified as either extraverts or introverts on the extraversion subscale of the Eysenck Personality Inventory (EPI), were presented with different levels of noise stimulation. During intermediate levels of noise, introverts exhibited greater heart rate reactivity than did extraverts. However, there were no differences between the two groups in heart rate reactivity under low or high level noise conditions. While introverts were more aroused at each level of intensity than were extraverts, extraverts preferred more intense noise levels than did introverts. These findings lent support to Eysenck's (1967) cortical arousal theory of extraversion. Geen's study demonstrated that introverts were at a higher level of arousal than were extraverts (i.e., introverts were generally more overaroused, while extraverts were generally more underaroused).

More recently, Pearson and Freeman (1991) examined the relation between extraversion and heart rate reactivity to a mental arithmetic task. Males who were identified on the basis of their scores on the EPI completed three different difficulty levels of a mental arithmetic task. Introverts were found to exhibit higher heart rate reactivity levels than extraverts across all three difficulty levels, again lending support to Eysenck's (1967) arousal theory of extraversion. Heart rate reactivity levels also increased with task difficulty, regardless of individual scores on the EPI. 


\section{$\underline{\text { Extraversion as a Predictor of Cardiovascular Reactivity to Stress }}$}

In order to examine the discrepancies found among the few existing studies examining the relation between extraversion and cardiovascular reactivity, the present study aims to examine two plausible models that may account for these differences.

One model that may explain the differences in the findings of the previous studies is the optimal arousal theory (Hebb, 1955). This theory postulates that every individual has his or her unique optimal level of arousal. In order to maintain that optimal level of arousal, an individual will engage in activities that will either increase or decrease his or her arousal level to maintain the optimum level. For instance, if an individual was underaroused, then he or she may engage in some type of stimulating activity in order to increase his or her level of arousal. On the other hand, if an individual was overaroused, then her or she may engage in some type of activity that has little stimulational value (e.g., reading a book) in order to decrease his or her level of arousal.

By applying this theory to the relation between extraversion and cardiovascular reactivity to stress, one would expect to observe a main effect with regard to the reactivity levels of introverts and extraverts during different types of tasks. More specifically, both extraverts and introverts would be expected to be more reactive to a social challenge than to a mundane nonsocial task, with introverts exhibiting greater reactivity to both tasks than extraverts (as partially supported by Pearson \& Freeman, 1991). However, according to Eysenck (1967), since introverts were overaroused, they would prefer to engage in tasks that decreased cortical arousal and 
extraverts would prefer tasks that increased cortical arousal (see hypothetical relation in Figure 1).

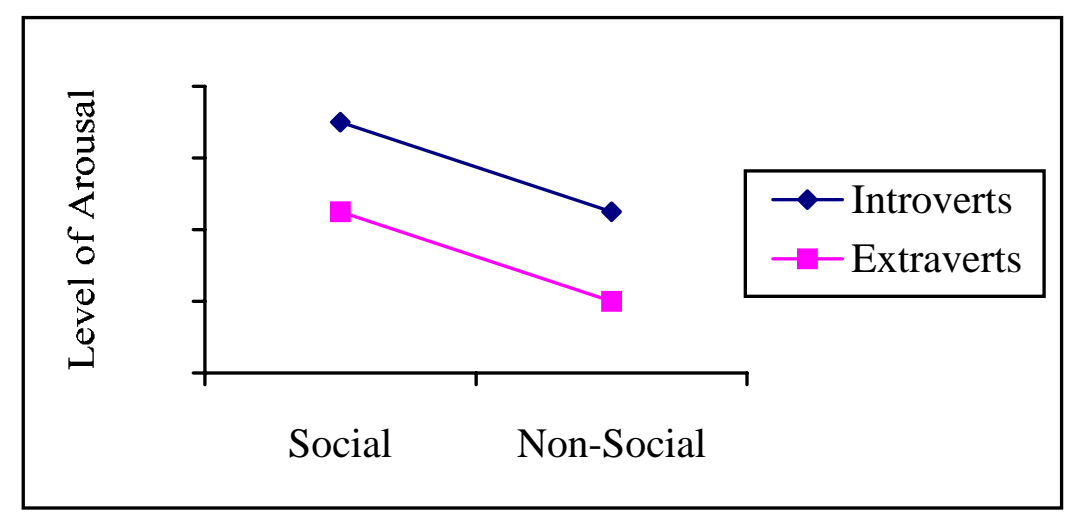

Figure 1. Hypothetical relation according to the optimal arousal theory.

Not all data support the optimal arousal theory (e.g., Gale, 1973; Geen, 1984). In contrast, a preferred task model might be more appropriate to describe the relation between extraversion and cardiovascular responding to stress. This model hypothesizes that tasks with which the individual is unfamiliar or non-preferred will elicit a greater cardiovascular response than will more familiar or preferred tasks. This may, in part, be due to the fact that an individual who is extraverted might avoid dull, non-social tasks because he or she finds them aversive. In contrast, an individual who is more introverted might avoid tasks that are more social because he or she finds those tasks to be aversive. Therefore, when individuals are placed into situations that they normally avoided and found aversive, they may likely respond by exhibiting larger cardiovascular reactions to the situation than to more familiar or preferred tasks. In this particular case, introverts would be expected to rate the social task to be more aversive than extraverts, and thus, they would be more reactive than extraverts during the task. Conversely, extraverts would rate the non-social task to be more aversive than introverts, and thus, they would be more 
reactive during the task than introverts (see hypothetical relation in Figure 2).

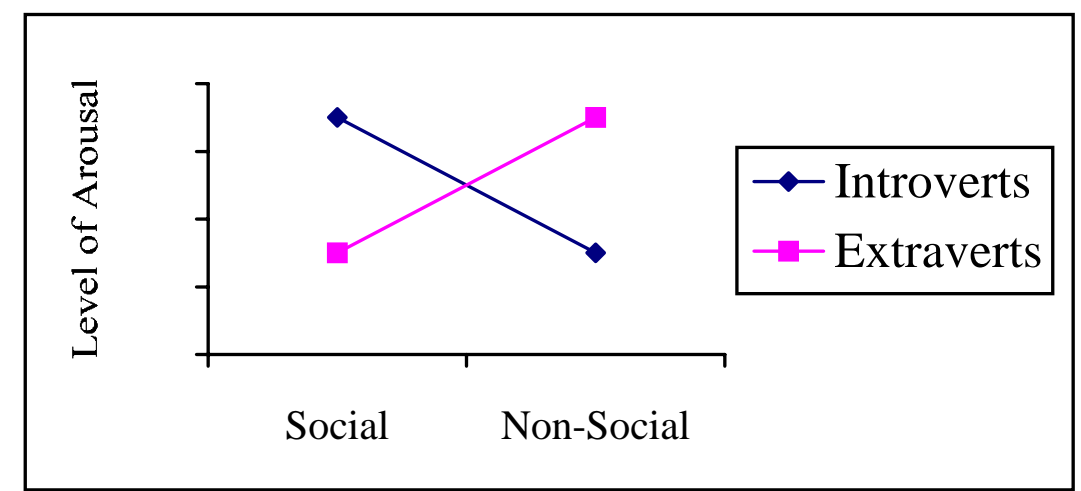

Figure 2. Hypothetical relation according to the preferred task model.

\section{Gender as a Predictor of Cardiovascular Reactivity to Stress}

Although gender effects are not commonly observed on measures of extraversion, gender differences in cardiovascular reactivity have been frequently reported (e.g., Girdler, Turner, Sherwood, \& Light, 1990; Matthews \& Stoney, 1988; Shapiro, Goldstein, \& Jamner, 1995; Stoney, Davis, \& Matthews, 1987). In general, females have been reported to exhibit greater HR reactions than males (e.g., Stone, Dembroski, Costa, \& McDougall, 1990) and males have been shown to exhibit greater BP reactions than females (e.g., Allen, Stoney, Owens, \& Matthews, 1993; Matthews \& Stoney, 1988; Stoney, Davis, \& Matthews, 1987). Based upon this body of literature, it is possible that differential effects between extraversion and cardiovascular reactivity to stress will be observed for males and females.

\section{Statement of Purpose}

Previous experimental psychophysiological studies have been conducted to examine the relation between extraversion and physiological arousal. However, little is actually known about the ways in which extraversion and cardiovascular reactivity to stress are related. The purpose of this study is to examine the effects of extraversion on cardiovascular reactivity during both social and non-social laboratory tasks. 
According to the optimal arousal theory, both extraverts and introverts would be expected to be more reactive to a social challenge than to a mundane non-social task, with introverts exhibiting greater reactivity to both tasks than extraverts. In contrast, a preferred task model would hypothesize that extraverts would be more reactive during a non-social task than introverts, and that introverts would be more reactive than extraverts during a social task.

The purpose of this study was to determine whether measures of cardiovascular responsivity conform more to the optimal level of arousal theory or to the preferred task model. In other words, this study explored which of these two models might best predict who is likely to be more reactive during a particular type of laboratory task. A secondary purpose was to examine potential gender effects that may moderate the relation between extraversion and cardiovascular reactivity. To this end, undergraduate males and females, selected on the basis of their scores on the extraversion subscale of the EPI, participated in a single laboratory session during which they were exposed to two challenges: a social task and a mundane non-social task.

\section{Method \\ $\underline{\text { Screening Phase }}$}

\section{$\underline{\text { Participants }}$}

Participants included 108 male and 184 female undergraduate students enrolled in psychology courses at West Virginia University. Each interested student completed the following questionnaires in exchange for extra credit points in his or her psychology course.

\section{$\underline{\text { Measures }}$}

Demographic Questionnaire. This instrument was intended to elicit information from each of the participants regarding their gender, age, date of birth, height, weight, (body mass index (BMI) was calculated by dividing the participants' weight in kilograms by their height ${ }^{2}$ in meters), race, marital status, number of years of education completed, medical history and current medications, parental medical history (specifically, any history of cardiovascular disease and related medications), exercise habits, and substance use (see Appendix A). Participants who reported having any medical conditions or using any medications or drugs that may interfere with 
an accurate assessment of cardiovascular reactivity were not contacted to participate in the laboratory phase of the study.

Eysenck Personality Inventory. The Eysenck Personality Inventory (EPI) was designed by Eysenck and Eysenck (1964) to measure two independent and pervasive dimensions of personality: (a) extraversion-introversion and (b) neuroticism-stability. The focus of the present study was on the extraversion-introversion dimension of the scale. Therefore, only that subscale of the questionnaire was utilized in the present study (see Appendix B). Briefly, extraversion refers to the outgoing, uninhibited, impulsive, and social behaviors of an individual. Introversion, on the other hand, refers to the withdrawn, inhibited, cautious, reserved, and non-social behaviors of an individual.

This subscale of interest, which measures the dimension of extraversion-introversion, consists of 29 questions to which the individual responds "yes" or "no." The measure was constructed on the basis of theoretically derived items, which underwent a series of factor analyses. One of the first scales constructed in this manner was the Maudsley Personality Inventory (MPI; Eysenck, 1962). Upon further factor analyses of the MPI items, only those questions that formed part of a single factor were used in the EPI (i.e., in each of its subscales). Satisfactory test-retest reliability and internal consistency have been demonstrated for the EPI. Test-retest reliability was assessed at approximately nine-month and twelve-month intervals. Correlations for the entire test ranged from .94 to .84 , respectively. Subscale correlations for the extraversion dimension similarly ranged from .97 to .82 , respectively. Alpha coefficients for the complete instrument have been reported as ranging from .75 to .91 , with extraversion subscale alpha coefficients falling on the lower end of the range at .75. Evidence for the relative independence of the two subscales of the EPI has been shown by the very small subscale intercorrelations found between these two subscales of extraversion and neuroticism, ranging from $\underline{r}=-.04$ to $\underline{r}=-.09$.

Furthermore, the extraversion subscale of the MPI and the EPI have been found to correlate with other instruments that have alleged to measure these same dimensions. For 
instance, the extraversion subscale of the MPI, from which the EPI was drawn, has been shown to correlate .79 with the Guilford Rhathymia scale (Eysenck \& Eysenck, 1964). Moreover, positive correlations between the extraversion subscale of the EPI and the California Personality Inventory $(\mathrm{CPI})$ subscales of Dominance $(\underline{\mathrm{r}}=.45)$, Sociability $(\underline{\mathrm{r}}=.53)$, Social Presence $(\underline{\mathrm{r}}=.60)$, and Self-Acceptance $(\underline{r}=.59)$ have been found.

In the present study, participants were asked to complete the EPI, which indicates the extent to which they endorse extraverted characteristics. Scores were calculated by adding up the total number of extraverted items that were endorsed as well as the total number of introverted items that were not endorsed. The final composite score was utilized in order to determine whether each individual exhibited more extraverted qualities or more introverted qualities. These individuals were selected via a tripartite split of the sample's total EPI scores. Those whose scores fell in the top third of all obtained scores (i.e., total EPI scores of greater than or equal to 19) for both males and females were classified as extraverts. Individuals were classified as introverts when their scores fell in the bottom third of all obtained total EPI scores (i.e., total scores of less than or equal to 13) for each gender.

Self-Reported Measures of Extraversion. Three questions were added to the Demographic Questionnaire in order to assess the relation between these questions and participants' scores on the EPI. The questions were as follows: (a) How many nights per week do you typically "go out"?, (b) How many nights per week do you typically go to the library?, and (c) Do you consider yourself to be more of an Extravert or Introvert?

\section{$\underline{\text { Procedure }}$}

After reading and signing an informed consent form, participants were asked to complete a demographics questionnaire as well as the Eysenck Personality Inventory (EPI; Eysenck \& Eysenck, 1964). Participants whose scores fell within the upper and lower third of all total EPI scores were contacted via telephone, had the experimental phase of the study described to them, and were offered extra credit for their participation. Those who declined participation in the second phase of the study were excluded from further participation. 


\section{Laboratory Phase}

\section{$\underline{\text { Participants }}$}

From the initial sample of participants, a total of 64 individuals (32 males and 32 females) were selected to participate in the second phase of the study. As described above, those students whose scores fell in the top third and bottom third of all the scores were asked to partake in the experimental phase of the study. An equal number of males and females were contacted in each extraversion group. Sixteen males and sixteen females were selected from the group of screening subjects characterized as "extraverted"; sixteen males and sixteen females were selected from the group of screening subjects characterized as "introverted."

Participants who indicated that they had chronic medical problems or that they used medications or drugs that would have affected or interfered with an accurate assessment of cardiovascular reactivity were excluded from the laboratory phase of the study $(\underline{\mathrm{N}}=8)$. Furthermore, individuals who were either unable to be contacted or who were not interested in involving themselves in the laboratory phase of the study were also excluded from further participation $(\underline{\mathrm{N}}=26)$. Individuals who smoked were not excluded; however, an attempt was made to include an equal number of smokers in each group. Furthermore, all participants were instructed to abstain from exercise, consuming food, alcoholic beverages, caffeine, or smoking for at least four hours before the experimental session. Once in the laboratory, all participants reported being compliant with these pre-session instructions.

\section{$\underline{\text { Measures }}$}

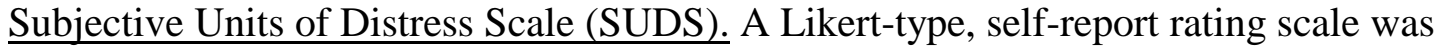
used with participants after each rest period and task period in order to assess each participants' subjective level of distress or arousal. The rating scale ranged from 0 ("least distress") to 10 ("most distress"). Participants indicated their level of distress and arousal on a blank form that contained the rating scale and was provided to them after each rest period and task period (see Appendix C). 


\section{$\underline{\text { Physiological Assessment and Apparatus }}$}

Heart Rate. A three lead polygraph (Grass Instruments, Model 7, Quincy, MA) was used to provide continuous measurement of HR during the rest and task periods of the experimental session. The physiological monitoring equipment attached to each participant consisted of three electrodes and their corresponding electrical leads. First, three electrodes were attached to the upper torso in order to obtain accurate and continuous heart rate measurements. The first electrode was placed just below each individual's shoulder and collarbone area. The second electrode was placed between each participant's second and third rib on their left side. The final (ground) electrode was placed on the right side of the torso. The areas were cleaned with cotton balls and rubbing alcohol prior to applying the electrodes. Electrical leads from the monitoring system were then attached to the electrodes.

Blood Pressure. SBP and DBP were assessed via an IBS (Industrial and Biomedical Sensors, Model SD 700A, Waltham, MA) BP monitor. A blood pressure cuff was placed around each individual's non-dominant upper arm. A microphone inside of the cuff, which was placed over the individual's brachial artery, detected the individual's SBP and DBP.

\section{$\underline{\text { Experimental Tasks }}$}

Social Task. The social task involved each participant presenting an impromptu persuasive speech on a controversial topic (i.e., abortion). Participants were allowed a 1 min preparation period before beginning the 3 min speech task. The speech task was videotaped in order to maintain the social context of the task. This task was labeled as a social task due to its simulation of a social context in everyday situations, as well as for its consistency with Eysenck's (1967) theory of extraversion. This task has been utilized in previous research examining cardiovascular reactivity (e.g., Davig, Larkin, \& Goodie, 2000).

Non-Social Task. In contrast, the non-social task involved the participants reading, outloud, from a passage copied from a technical manual. Consistent with the social task, this task continued for a total of $3 \mathrm{~min}$. This task has not been used in previous research examining 
cardiovascular reactivity; however, it represents a mundane task that requires continuous engagement, but had little or no social connotation.

\section{$\underline{\text { Procedure }}$}

Each participant was directed to a room in the laboratory containing a reclining chair in which they were seated during the entire experimental session. Prior to being seated, participants had the physiological monitoring equipment attached, as described above.

Following the attachment of the physiological monitoring equipment, the experimental session began with a 10-min baseline rest period. Participants were instructed to rest comfortably during this time. Physiological measures (i.e., heart rate and blood pressure) were also taken during this time frame. Heart rate (HR) was measured continuously during the rest period while systolic blood pressure (SBP) and diastolic blood pressure (DBP) were measured every two minutes of the rest period. At the end of the initial rest period, participants rated their level of distress via the self-report Likert-type SUDS (Subjective Units of Distress) rating scale.

Following the resting measurements, participants were instructed, via audio taped instructions, to engage in a series of two tasks. The order of the delivery of each of the tasks was counterbalanced between introverts and extraverts, as well as between males and females. Prior to each task, participants listened to the instructions for the task via an audio taped recording. Each task was followed by a 6-min rest period during which participants were instructed to rest as comfortably as possible.

Physiological measurements were obtained throughout the task and rest periods of the session. HR was measured continuously during the task and rest periods while SBP and DBP were monitored every two minutes of the task and rest periods, beginning at minute 0 . Furthermore, participants were asked to rate their level of distress after each of the rest periods and tasks via a SUDS rating scale. 
Upon completing the experimental portion of the study, participants were provided with forms to give to their instructors in order to receive extra credit points in their courses. Participants were also provided with a brief description and rationale of the purpose of the study and given the opportunity to ask questions regarding the study.

\section{Results}

Analytic results performed for self-reported measures of extraversion (Eysenck Personality Inventory, number of nights per week that the participants "go out," number of nights per week that the participants go to the library, and whether the participants considered themselves to be an "extravert" or an "introvert") are described first. Then, characteristics of the sample are presented. Procedures utilized for the reduction of the cardiovascular data will be described, immediately followed by the results of the analyses performed on the cardiovascular variables (HR, SBP, and DBP) and self-reported levels of distress (SUDS). An alpha level of .05 was adopted for all analyses.

\section{Measures of Extraversion}

Because participants were classified and divided into groups based upon their EPI scores, analyses were performed in order to confirm that the two classification groups (extraverts and introverts) had significantly different scores on the questionnaire. Univariate Gender x Extraversion ANOVAs confirmed that the groups were significantly different with regard to their scores on the EPI, $\underline{F}(1,60)=584.77, \underline{p}<.001$.

As for EPI scores overall, similar to reported norms for college students $(\underline{M}=13.10, \underline{S D}$ =4.10) (Eysenck \& Eysenck, 1964), the current sample mean score on the EPI was $15.80(\underline{\mathrm{SD}}=$ 7.16). Moreover, EPI mean scores for the selected sample (for extraverts, $\underline{M}=22.5, \underline{S D}=1.88$ and for introverts, $\underline{M}=9.1, \underline{S D}=2.66$ ) were similar to EPI mean scores for all students who participated in the screening phase of the study (for extraverts, $\underline{M}=23.84, \underline{S D}=1.37$ and for introverts, $\underline{M}=8.0, \underline{\mathrm{SD}}=2.08$ ). Slight differences may be attributable to the number of individuals who were either unable to be contacted or who refused further participation in the study. 
Furthermore, analyses of self-reported measures of number of nights per week that the participants "go out," number of nights per week that the participants go to the library, and whether the participants considered themselves to be an "extravert" or an "introvert" were examined in order to determine whether they were consistent with the participants' categorization as extraverts and introverts. Analyses confirmed that the groups differed in the number of nights per week that they each "go out," $\underline{F}(1,60)=8.96, \underline{p}=.004$, and go to the library, $\underline{\mathrm{F}}(1,60)=7.221, \underline{\mathrm{p}}=.009$, and whether they considered themselves to be either an “extravert" or an "introvert," $\chi^{2}(1, \underline{N}=61)=23.25, \underline{p}<.001$. As expected, extraverts went out more than introverts, went to the library less frequently than introverts, and considered themselves to be extraverts. Males also reported "going out" more frequently than did females, $\underline{F}(1,60)=7.79, \underline{p}=.007$. No other main effects or interactions were significant (see Table 1$)$.

\section{$\underline{\text { Subject Characteristics }}$}

In order to assess for potential pre-existing differences between the groups, univariate Gender x Extraversion ANOVAs were utilized to examine the parametric demographic characteristic variables of age, height, weight, calculated body mass index, and total number of years of education completed. Categorical demographic characteristic variables of race, marital status, presence of a chronic medical condition, family history of cardiovascular disease, regular medication use, current exercise, current tobacco use, current alcohol use, and current recreational drug use were also analyzed via the use of Chi square tests.

As expected, analyses indicated that males were significantly taller, $\underline{F}(1,60)=80.37$, $\underline{\mathrm{p}}<$ .001 , and heavier, $\underline{\mathrm{F}}(1,60)=25.16, \underline{\mathrm{p}}<.001$, than females. However, BMI was not found to be significantly different between males and females. Further analyses found no significant findings for age, total number of years of education completed, amount of monthly exercise (among those who exercised), amount of monthly tobacco use (among those who used tobacco-containing products), or amount of monthly recreational drugs use (among those use who recreational drugs), between either males and females or extraverts and introverts (see Tables $2 \& 3$ ). 
Analyses revealed that among those participants who drink alcohol, males, $\underline{F}(1,38)=$ $7.22, \underline{p}=.011$, and extraverts, $\underline{\mathrm{F}}(1,38)=5.76, \underline{\mathrm{p}}=.021$, consumed significantly more alcohol than females and introverts, respectively. However, because the participants denied drinking alcohol within four hours of the experiment, it seemed unlikely that either of these variables would have an effect on the dependent variables of the study and thus it was unnecessary to use these variables as covariates in further analyses.

Chi square analyses of categorical variables revealed no significant differences with regard to race, marital status, presence of a chronic medical condition, family history of cardiovascular disease, or current tobacco use. However, females did report significantly more often than males that they were currently taking medication on a regular basis, $\chi^{2}(1, \underline{N}=64)=$ $4.73, \underline{p}=.03 ; 60 \%$ of those who reported taking medications were taking birth control pills. Moreover, extraverts reported significantly more often than introverts that they were currently exercising, $\chi^{2}(1, \underline{\mathrm{N}}=64)=3.93, \underline{\mathrm{p}}=.048$, drinking alcohol regularly, $\chi^{2}(1, \underline{\mathrm{N}}=64)=12.65, \underline{\mathrm{p}}<$ .001 , and using recreational drugs, $\chi^{2}(1, \underline{\mathrm{N}}=64)=5.85, \underline{\mathrm{p}}=.016$. No other significant differences were found (see Table 4). Because the participants were instructed to not engage in any of these activities within four hours of the experiment, it seemed unlikely that any of these variables would have an effect on the dependent variables of the study. Thus, it was unnecessary to use these variables as covariates in subsequent analyses.

\section{$\underline{\text { Data Reduction }}$}

HR data (in beats per minute (bpm)) were obtained every minute during each task and intervening rest period. Of the initial rest period, which lasted 10 minutes for each participant, only the last six minutes were utilized for data analysis, not only to make the length of each rest period uniform, but also to allow for the subjects to acclimate to the laboratory environment. The HR data were further reduced by averaging across the six readings for each minute of the rest periods: (a) Pre Social Rest Period and (b) Pre Non-Social Rest Period; and across the three readings for each minute of the two tasks: (a) Social Task Period and (b) Non-Social Task Period. 
SBP and DBP data (in $\mathrm{mmHg}$ ) were determined every two minutes during each task and intervening rest period. Based on the criteria described by Marler, Jacob, Lehoczky, and Shapiro (1988), BP values were determined to be inaccurate when: (a) SBP <70 or > $250 \mathrm{~mm} \mathrm{Hg}$; (b) DBP $<45$ or $>150 \mathrm{~mm} \mathrm{Hg}$; and/or (c) SBP/DBP $<(1.065+[0.00125 \times \mathrm{DBP}])$ or $>3$. Similar to the HR data, only the last six minutes of the initial 10-min rest period were utilized. By averaging across the three readings for each of the rest periods and across the two readings for each of the tasks, mean SBP and DBP measures were obtained for each participant for each of the four periods described above.

\section{$\underline{\text { Resting Cardiovascular and Self-Report Measures }}$}

During the initial rest period, a univariate Gender $\mathrm{x}$ Extraversion ANOVA revealed no significant differences in resting HR. For the initial rest period, the ANOVA on resting SBP found a significant main effect for Gender, $\underline{F}(1,60)=32.92, \underline{p}<.001$. Females had a significantly lower resting $\mathrm{SBP}(\underline{\mathrm{M}}=109.6 \mathrm{~mm} \mathrm{Hg}, \underline{\mathrm{SD}}=10.14)$ than males $(\underline{\mathrm{M}}=122.9 \mathrm{~mm} \mathrm{Hg}$, $\underline{\mathrm{SD}}=8.00)$. No other main effects or interactions were significant. The univariate ANOVA for the initial resting DBP yielded no significant main effects or interactions. A univariate ANOVA for the initial rest period SUDS rating revealed no significant main effects or interactions.

\section{Measures of Cardiovascular Reactivity}

A series of $2 \times 2 \times 2$ [Gender (male, female) x Extraversion (extravert, introvert) $\times$ Task (social, non-social)] analyses of covariance (ANCOVAs) were performed on the HR, SBP, and DBP dependent variables, covarying pre-task resting levels for each variable.

Heart Rate. ANCOVA analyses conducted on average HR during each of the two tasks, using the pre-task average $\mathrm{HR}$ as covariates, yielded a significant main effect for Task, $\underline{\mathrm{F}}(1,59)=$ 45.84, $\mathrm{p}<.001$. Adjusted mean HRs during the social task $(\underline{\mathrm{M}}=90.8 \mathrm{bpm}, \underline{\mathrm{SD}}=13.56)$ were significantly greater than HRs during the non-social task $(\underline{\mathrm{M}}=84.5 \mathrm{bpm}, \underline{\mathrm{SD}}=12.36)$. No other main effects or interactions were significant. Means and standard deviations for HR during each of the pre-task rest periods and task periods are provided in Table 5 (for ANCOVA summary table, see Appendix D). 
Systolic Blood Pressure. ANCOVA analyses conducted on average SBP during each of the two tasks, using the pre-task average SBP as covariates, revealed a significant main effect for Task, $\underline{\mathrm{F}}(1,59)=78.37, \underline{\mathrm{p}}<.001 . \mathrm{SBP}$ during the social task $(\underline{\mathrm{M}}=137.0 \mathrm{~mm} \mathrm{Hg}, \underline{\mathrm{SD}}=17.98)$ was significantly greater than SBP during the non-social task $(\underline{\mathrm{M}}=126.2 \mathrm{~mm} \mathrm{Hg}, \underline{\mathrm{SD}}=15.49)$. No other main effects or interactions were significant. Table 6 presents the means and standard deviations for SBP during each of the pre-task rest periods and task periods (for ANCOVA summary table, see Appendix E).

Diastolic Blood Pressure. ANCOVA analyses conducted on average DBP during each of the two tasks, using the pre-task average DBP as covariates, demonstrated a significant main effect for Task, $\underline{\mathrm{F}}(1,59)=5.46, \underline{\mathrm{p}}=.023$. Adjusted mean DBP during the social task $(\underline{\mathrm{M}}=79.9$ $\mathrm{mm} \mathrm{Hg}, \underline{\mathrm{SD}}=9.46)$ was significantly greater than DBP during the non-social task $(\underline{\mathrm{M}}=69.9 \mathrm{~mm}$ $\mathrm{Hg}, \underline{\mathrm{SD}}=8.70)$. No other main effects or interactions significant. Means and standard deviations for DBP during each of the pre-task rest periods and task periods are illustrated in Table 7 (for ANCOVA summary table, see Appendix F).

\section{$\underline{\text { Self-Reported Measures of Distress }}$}

Similar to the cardiovascular measures, a Gender $\mathrm{x}$ Extraversion $\mathrm{x}$ Task analysis of variance (ANCOVA) was performed on the self-reported measures of distress (SUDS ratings), utilizing pre-task ratings as covariates. Using the pre-task SUDS ratings as covariates, ANCOVA analyses conducted on SUDS ratings given after each of the two tasks revealed a significant main effect for Task, $\underline{F}(1,59)=135.77, \underline{p}<.001$. SUDS ratings after the social task $(\underline{\mathrm{M}}=4.8, \underline{\mathrm{SD}}=$ 2.33) were higher than SUDS ratings after the non-social task $(\underline{\mathrm{M}}=1.7, \underline{\mathrm{SD}}=1.63)$. No other main effects or interactions were significant. Table 8 offers the means and standard deviations for SUDS ratings after each of the task periods and pre-task rest periods (for ANCOVA summary table, see Appendix G).

Correlation coefficients were also calculated between SUDS ratings on each task and the corresponding cardiovascular reactivity measures. Correlation coefficients for the social task 
were: HR, $\underline{\mathrm{r}}(64)=.130, \mathrm{p}=.306, \mathrm{SBP}, \underline{\mathrm{r}}(64)=.213, \mathrm{p}=.091$, and DBP, $\underline{\mathrm{r}}(64)=.026, \mathrm{p}=.838$. Similarly, correlation coefficients for the non-social task were: HR, $\underline{r}(64)=-.226, p=.073, \mathrm{SBP}$, $\underline{\mathrm{r}}(64)=-.228, \mathrm{p}=.070$, and DBP, $\underline{\mathrm{r}}(64)=-.098, \mathrm{p}=.441$. Overall, self-reported measures of distress did not correlate with cardiovascular measures of reactivity.

\section{Discussion}

Due to the importance of cardiovascular reactivity to stressors and its relation to the development of disease, the purpose of the present study was to examine the effects of another behavioral characteristic, extraversion, on cardiovascular reactivity to both a social and nonsocial laboratory task. This exploratory study was conducted in order to investigate whether measures of cardiovascular responsivity conformed to the optimal level of arousal theory or to the preferred task model. In other words, the purpose of the study was to determine which of these two models best predicted the relation between extraversion and cardiovascular reactivity to mental stress. A secondary purpose of the study was to determine whether gender was associated with any differential cardiovascular response to the tasks.

Behavioral Characteristics Associated with Cardiovascular Reactivity

While previous experimental psychophysiological studies have explored the relation between extraversion and physiological arousal, little is known regarding the ways in which extraversion and cardiovascular reactivity to stress are related. The few studies that attempted to examine this relation have yielded contradictory findings (e.g., Gale, 1973; Glass, 1983; Geen, 1984; Pearson \& Freeman, 1991). Likewise, the overall analyses of the data from the present study are unable to shed much light upon this relation. The present findings suggest that little, if any, relation exists between extraversion and cardiovascular reactivity to stressors of any type.

Unlike the present study, previous investigations have utilized only male participants. However, given that few gender differences were observed in the present study, general comparisons among these studies can be made. 
The present findings are in direct contrast to those of Pearson and Freeman (1991) and Geen (1984). Both of these previous investigations found extraverts and introverts to be differentially responsive to laboratory stimuli. Although both studies utilized the EPI to classify individuals as either extraverts or introverts, they differed in that they used varying levels of a single stimulus rather than different stimuli to evoke differential heart rate responses (blood pressure responses were not measured in either previous study). Pearson and Freeman found introverts to exhibit higher heart rate reactivity across varying levels of a mental arithmetic task than extraverts. Similarly, Geen found the same significant differential response, but only during intermediate levels of noise stimulation, even though introverts were generally more aroused at each level of stimulation than were extraverts. Unlike the present study, these findings supported the optimal arousal theory of extraversion.

According to the optimal arousal theory, which follows that of Eysenck's (1967) cortical arousal theory of extraversion, participants, regardless of extraversion classification, would be expected to be more reactive to a social challenge than to a mundane non-social task, with introverts exhibiting greater reactivity to both tasks than extraverts, as evidenced by Geen (1984) and Pearson and Freeman (1991). In contrast, a preferred task model hypothesized that extraverts would be more reactive during a non-social task than introverts, and that introverts would be more reactive than extraverts during a social task. The present study did not obtain any significant findings with regard to any of the cardiovascular measures taken that would lend support for either of these two approaches. Though the large variance within each group (i.e., extraverts and introverts), as demonstrated by the standard deviations for each dependent variable, may be partially responsible for the lack of findings in this area.

If the observed means for each of the groups' cardiovascular reactivity measures are examined, it is noticeable, but not significant, that they go in the direction implied by the optimal arousal theory. When the means for each of the groups were examined, introverts demonstrated slightly higher HR, SBP, and DBP than extraverts. However, the reader is cautioned that this is merely an observation and not a statistically significant difference. While these findings may lean in the direction of the optimal arousal theory, no significant findings were observed in the present 
study that were able to lend support to either theory of predicting differential reactivity to social and non-social laboratory challenges based upon an individuals extraversion classification.

Such findings substantiate the lack of any consistent findings of differences in cardiovascular reactivity when extraversion classification and task type are taken into consideration. Even as demonstrated by Glass and colleagues (1983), who utilized the 16 PF inventory, rather than the EPI, to classify individuals on extraversion, no heart rate or blood pressure reactivity differences were found among individuals based upon their extraversion status. As with the present study, this study presented participants with two different laboratory mental stressors (i.e., mental arithmetic and a modified Stroop task) and no cardiovascular reactivity differences were found.

Perhaps the explanation for these contradictory findings lies in the previous speculations of Gale (1973). In a review of studies examining the relation between extraversion and EEG arousal, Gale found conflicting results and postulated that this might be due to the types of tasks in which the individuals were involved, with introverts generally being more aroused than extraverts except when in either very interesting situations (thereby peaking the arousal levels of extraverts) or very boring situations (thereby causing excessive levels of stress and/or selfstimulatory activities to increase arousal). Perhaps the extraverts in the present study found the entire laboratory session to be so boring and devoid of interest that they engaged in selfstimulatory activities and/or were so stressed as to increase their arousal levels such that no cardiovascular reactivity differences, if existing, were evidenced.

A related variable to consider is an extension of the one already suggested by Gale (1973) regarding the diverse array of tasks that have been invoked across the different studies that have examined the relation between extraversion and physiological activity. Geen (1984) found significant differences during the intermediate level of a three-level noise stimulation task. Pearson and Freeman (1991) demonstrated differences across varying difficulty levels of a mental arithmetic task. In 1983, Glass and colleagues also utilized a mental arithmetic task in addition to a modified Stroop task. The social and non-social tasks of the present study clearly 
differed from those used in these previous studies, which may also explain the lack of significant findings. Furthermore, this may alter the comparisons that can be appropriately made among the studies.

Yet another explanation may better account for the lack of significant findings in the present study. Perhaps the introverts in the present study were not stressed enough to provoke significant cardiovascular reactions. Given the constraints within which the study was conducted (i.e., via the kindness of undergraduate student participants), participants were approached via "nice" and reassuring interactions in order to encourage them to partake in the study. This may have set the study up such that the participants were not distressed or threatened at all by either of the experimental manipulations. As evidenced by the SUDS ratings, even during the more distressing of the two tasks (i.e., the social task), ratings were on the low end of the scale. Perhaps "harassment" of the participants or a sense of competition is necessary to evoke higher levels of cardiovascular reactivity during these types of laboratory tasks. Yet, neither Geen (1984) nor Pearson and Freeman (1991) harassed or prompted their participants to be competitive and they were still able to uncover differences in cardiovascular reactivity between extraverts and introverts.

The explanation for the lack of differences in the present study and the contradictory findings of previous studies may lie in yet another arena. While studies may have demonstrated differential responding between extraverts and introverts with regard to cortical arousal, perhaps those differences do not extend to the periphery of the individual. In other words, while there may be differences between extraverts and introverts with regard to cortical arousal, as proposed by Eysenck (1967), there may be no differences between extraverts and introverts with regard to peripheral autonomic nervous system activity, as measured by cardiovascular reactivity to mental stressors.

\section{Gender Differences in Cardiovascular Reactivity}

Most researchers generally agree that gender differences exist within the physiological parameters of HR and BP (e.g., Girdler et al., 1990; Matthews \& Stoney, 1988; Shapiro et al., 
1995; Stoney et al., 1987). More specifically, the general consensus is that women exhibit greater reactivity in HR while men exhibit greater reactivity in BP when exposed to stressors (Allen et al., 1993; Stone et al., 1990; Vogele et al., 1997). Nevertheless, the present study found little to support these claims.

Unlike prior studies (e.g., Stone et al., 1990), the present study found no gender differences in regard to resting HR or HR responses to mentally stressful tasks between males and females. The lack of any findings in this area may be due in part to the wide range of HR variability within the study sample. While the difference between the average resting HR for males $($ Mean $=76.4, \mathrm{SD}=14.41)$ and females $($ Mean $=79.6, \mathrm{SD}=9.95)$ was apparent, the wide range of HRs may account for the lack of detecting significant differences. Resting HRs were observed from $49.7 \mathrm{bpm}$ to $106.7 \mathrm{bpm}$, suggesting that our sample varied considerably in aerobic fitness. Comparable HR variability was exhibited during each of the task and rest periods.

Consistent with previous research (e.g., Allen et al., 1993; Girdler et al., 1990), males exhibited significantly higher SBP while resting than females. However, unlike previous findings (e.g., Matthews \& Stoney, 1988; Stoney et al., 1987), no significant gender differences were found with regard to SBP reactivity to stressors. Again, these findings may be attributed, at least in part to the wide range of SBPs exhibited by the current sample. Resting SBPs ranged from $92.3 \mathrm{~mm} \mathrm{Hg}$ to $138.3 \mathrm{~mm} \mathrm{Hg}$. Comparable effects were apparent across all experimental periods.

With regard to resting DBP and DBP response, no significant gender differences were observed. Such findings corroborated the lack of any consistent findings of gender differences in DBP reactivity (e.g., Allen et al., 1993; Girdler et al., 1990, Shapiro et al., 1995; Vogele et al., 1997; Stone et al., 1990). As with the other measures of cardiovascular reactivity measured in the current study, it is also possible that this lack of gender differences in resting DBP and DBP response was due to the variability of DBPs present within the groups. In contrast to findings for $\mathrm{HR}$ and SBP, however, it was evident that average resting DBP for males $(\mathrm{Mean}=68.8, \mathrm{SD}=$ $8.88)$ and females $($ Mean $=68.6, \mathrm{SD}=8.50)$ were not significantly different. 
Given the range of variability among cardiovascular measures observed in the present study, previous studies that have utilized similar laboratory tasks were examined in order to compare indices of variability. As illustrated in Table 9, previous studies (e.g., Davig et al., 2000; Frazer, Larkin, \& Goodie, in press) utilizing similar tasks appear to have demonstrated less BP variability across resting and task periods than the present study, potentially explaining the lack of significant findings within the present study. HR variability in the current study was more similar to HR variability observed in the other studies conducted in the same laboratory.

\section{$\underline{\text { Relation of Laboratory Tasks to Cardiovascular Reactivity and Levels of Distress }}$}

Findings of the present study supported those of previous researchers who found that overall, participants were more reactive to a social task than to a non-social task (e.g., Davig et al., 2000). Present findings indicated that regardless of gender or extraversion classification, participants were more reactive during the social task than during the non-social task. This was true not only for HR measures of reactivity, but also for BP measures of reactivity. HR, SBP, and DBP were all significantly greater during the social task than during the non-social task across all participants.

Overall, these findings indicated that the individuals in the study found the social task to be more arousing than the non-social task. Given that the very act of vocalizing can increase an individual's HR, as well as SBP and DBP, and that participants were instructed to verbalize for the entire 3 min during both tasks, it can be stated with greater confidence that the reactivity differences found between the two tasks were not related to mere verbalization. In general, individuals found the social task to be more arousing than the non-social task.

Not unlike cardiovascular measures of reactivity, no significant differences were found in regard to resting SUDS ratings, irrespective of gender. Nevertheless, analyses revealed that participants rated their distress level as significantly higher for the social task than for the nonsocial task. Although no hypotheses were made with regard to individuals' subjective levels of distress during each of the tasks, it is interesting to find such a difference. These findings lend 
further support to the notion that individuals found the social task to be more distressing than the non-social task. In this regard, subjective and physiological indicators of stress were congruent.

\section{Limitations of the Study}

There are several factors that limit direct comparisons with previous studies. As previously mentioned, the diverse array and types of tasks employed across studies obviously casts a shadow over the unequivocal comparison among the studies. Each study utilized a different task for measuring cardiovascular reactivity to stress and thus to determine the relation between extraversion and reactivity. The present study utilized two tasks, based on Eysenck's theory of arousal, which had not been used in previous research of this type.

A related concern is that of the actual level of distress that was produced during the experimental session was less than optimal. Given that the success of this study relied upon the willingness of undergraduate student participants to enroll in the research project, the researcher continually approached potential participants in a pleasant, and undoubtedly reassuring, manner such that students were not so distressed as to decline to participate. These interactions may have created a non-threatening environment before the experimental session even took place, such that individuals were not significantly distressed by the experimental manipulations, as they may have been in other studies. To this end, perhaps the participants could have been harassed, or a more provoking and genuine social task, or even a task that enhanced competition or challenge may have evoked greater cardiovascular responses to mental stress. Furthermore, there is always the questionable generalizability of these findings to those individuals who declined to participate.

Another issue that may be considered as a limitation is the way in which individuals were classified as either extraverts or introverts. Different studies have utilized different methods of classification, with equally different results. Perhaps, the extraversion subscale of the EPI is not sensitive enough on its own to differentiate between those individuals who are underaroused and those who are overaroused, as proposed by Eysenck (1967). Conceivably, it is a combination of qualities that differentiate between those two types of individuals. Thus, rather than administering only the extraversion subscale of the EPI, the entire EPI could be administered and 
individuals chosen based upon combined high and combined low scores on the extraversion subscale and the neuroticism subscale. An alternate option might be to validate the individual's self-reported score on the EPI by having a close friend or relative complete the questionnaire evaluating the participant as well.

Another potential limitation to the present study may be related to the sensitivity of the equipment used to measure BP. While the polygraph was able to obtain continuous recordings of heart rate, continuous BP measures were not obtained. Consequently, the measures were less sensitive to fluctuations in BP. Perhaps more sensitive equipment would be able to detect differential cardiovascular responses between extraverts and introverts. It is also possible that more specific measures of peripheral autonomic nervous system arousal, like pre-ejection period of the cardiac cycle or electrodermal activity, would have yielded differential responding between groups. As these variables were not measured in this study, it will be up to future research to examine this possibility.

A final consideration is that even though the design of the present study was to examine the difference in arousal levels between extraverts and introverts, direct measurement of that arousal was not conducted. It is highly conceivable that the two groups of individuals were differentially cortically aroused, but that cortical arousal did not extend to the periphery of the individual and therefore was not detected in the present study. In other words, cardiovascular reactivity, as a measure of peripheral autonomic nervous system activity, to mental stressors may not be an accurate proxy for cortical arousal. More direct measurements of cortical arousal may better address the questions of Eysenck's theory of arousal.

\section{Directions for Future Research}

With the conflicting results among studies of this nature and in light of the present findings, it seems appropriate to state that extraversion might not be a relevant behavioral factor with regard to cardiovascular reactivity. Even so, due to the variability of resting HR and BP measures obtained in this study, future investigations in this area, if conducted, would benefit from a better assessment of aerobic fitness. By asking more specific questions and better 
assessing aerobic fitness, this factor could be better controlled for in analyses of cardiovascular reactivity differences.

Further research may also be necessary to determine whether certain tasks are more appropriate for identifying cardiovascular reactivity differences between extraverts and introverts. A related concern may be to reduce the overall pleasantness of the situation such that individuals respond in a more realistic fashion to the laboratory stressors. This may be accomplished by providing gentle harassment during the social task, or by designing a more realistic and challenging social task, or even by creating a sense of competition among participants.

Additional research in this area may also want to employ multiple measures of extraversion characteristics, completed by both potential participants as well as significant others, in order to better confirm the individuals' extraversion classification. Additional measures of other potentially related constructs might also help to better differentiate among those individuals who are more extraverted and potentially underaroused versus those who are more introverted and potentially overaroused.

A final consideration for future investigations would be to consider obtaining more direct and concomitant measures of cortical arousal to these laboratory tasks. Given that peripheral measures of autonomic arousal, via cardiovascular reactivity, provided no insight into potential differences between extraverts and introverts, the next logical step seems to be to go directly to the source. This could be accomplished by measuring the actual theorized cortical arousal differences via psychophysiologic assessment techniques and equipment.

Given the overall results of the present and previous studies, further investigations would be wise to focus more broadly upon established personality factors, which may be contributing to cardiovascular reactivity to stress, as well as to other lifestyle factors related to the development of cardiovascular disease. Given the current prevalence of cardiovascular disease and its ranking as the one of the leading causes of death in the United States and other industrialized nations 
(American Heart Association, 1997), understanding this disease seems of utmost importance. In order to do this, researchers have begun to examine not only the risk factors (e.g., American Heart Association; Jenkins, 1988) and physiological mechanisms related to the development of the disease (e.g., Allan \& Scheidt, 1996), especially cardiovascular reactivity to stress (e.g., Barnett et al., 1997; Corse, et al., 1982; Manuck, 1994), but also the behavioral characteristics associated with its development (e.g., Barefoot, Larsen, Von der Leith, \& Schroll, 1995; BoothKewley \& Friedman, 1987; Siegel, 1984). By understanding these relations, the ability to intervene and prevent the detrimental consequences of this disease becomes a more realistic goal. To this end, this study has contributed to the area of research by potentially ruling out extraversion as one of those relevant behavioral characteristics related to the development of cardiovascular disease and encouraging the investigation of other potentially relevant characteristics. 


\section{References}

Allan, R., \& Scheidt, S. (1996). Empirical basis for cardiac psychology. In R. Allan \& S. Scheidt (Eds.), Heart and mind: The practice of cardiac psychology (pp. 63-123). Washington, DC: American Psychological Association.

Allen, M. T., Stoney, C. M., Owens, J. F., \& Matthews, K. A. (1993). Hemodynamic adjustments to laboratory stress: The influence of gender and personality. Psychosomatic Medicine, 55, 505-517.

American Heart Association. (1997). Heart and stroke statistical update. Dallas, TX: Author.

Andreassi, J. L. (1995). Psychophysiology: Human behavior and physiological responses. Hillsdale, NJ: Lawrence Erlbaum Associates.

Barefoot, J. C., Larsen, S., Von der Lieth, L., \& Schroll, M. (1995). Hostility incidence of acute myocardial infarction, and mortality in a sample of older Danish men and women. American Journal of Epidemiology, 142, 477-484.

Barnett, P. A., Spence, D., Manuck, S. B., \& Jennings, J. R. (1997). Psychological stress and the progression of carotid artery disease. Journal of Hypertension, 15, 49-55.

Barnett, P. H., Hines, E. A., Schirger, A., \& Gage, R. P. (1963). Blood pressure and vascular reactivity to the cold pressor test. Journal of the American Medical Association, 183, 845848.

Booth-Kewley, S., \& Friedman, H. S. (1987). Psychological predictors of heart disease: A quantitative review. Psychological Bulletin, 101, 343-362.

Corse, C. D., Manuck, S. B., Cantwell, J. D., Giordani, B., \& Matthews, K. A. (1982). Coronaryprone behavior pattern and cardiovascular response in persons with and without coronary heart disease. Psychosomatic Medicine, 44, 449-459.

Davig, J. P., Larkin, K. T., \& Goodie, J. L. (2000). Does cardiovascular reactivity to stress measured in the laboratory generalize to thesis and dissertation meetings among doctoral students? International Journal of Behavioral Medicine, 7, 216-235.

Dembroski, T. M., MacDougall, J. M., \& Lushene, R. (1979). Interpersonal interaction and cardiovascular response in Type A subjects and coronary patients. Journal of Human Stress, $5,28-36$.

Eysenck, H. J. (1967). The biological basis of personality. Springfield, Illinois: Charles Thomas.

Eysenck, H. J., \& Eysenck, S. B. G. (1964). Manual of the Eysenck Personality Inventory. London: University of London Press. 
Frasure-Smith, N., Lesperance, F., \& Talajic, M. (1995). The impact of negative emotions on prognosis following myocardial infarction: Is it more than depression? Health Psychology, 14, 388-398.

Frazer, N. L., Larkin, K. T., \& Goodie, J. L. (in press). Do behavioral responses mediate or moderate the relation between cardiovascular reactivity to stress and parental history of hypertension? Health Psychology.

Gale, A. (1973). The psychophysiology of individual differences: Studies of extraversion and the EEG. In P. Kline (Ed.), New Approaches in Psychological Measurement. London: John Wiley.

Geen, R. G. (1984). Preferred stimulation levels in introverts and extraverts: Effects on arousal and performance. Journal of Personality and Social Psychology, 46, 1303-1312.

Girdler, S. S., Turner, J. R., Sherwood, A., Light, K. C. (1990). Gender differences in blood pressure control during a variety of behavioral stressors. Psychosomatic Medicine, 52 , 571-591.

Glass, D. C., Lake, C. R., Contrada, R. J., Kehoe, K., \& Erlanger, L. R. (1983). Stability of individual differences in physiological responses to stress. Health Psychology, 2, $317-$ 341.

Hastrup, J. L., Light, K. C., \& Obrist, P. A. (1982). Parental hypertension and cardiovascular response to stress in healthy young adults. Psychophysiology, 19, 615-622.

Hebb, D. O. (1955). Drives and the C. N. S. (conceptual nervous system). Psychological Review, $\underline{62}, 243-254$.

Hollenberg, N. K., Williams, G. H., \& Adams, D. F. (1981). Essential hypertension: Abnormal renal, vascular, and endocrine responses to a mild psychological stimulus. Hypertension, 2, $11-17$.

Jenkins, C. D. 91988). Epidemiology of cardiovascular disease. Journal of Consulting and Clinical Psychology, 56, 324-332.

Kannel, W. B. (1996). Blood pressure as a cardiovascular risk factor. Journal of the American Medical Association, 275, 1571-1576.

Keys, A., Taylor, H. L., Blackburn, H., Brozek, J., Anderson, J. T., \& Simonson, E. (1971). Mortality and coronary heart disease among men studied for 23 years. Archives of Internal Medicine, 128, 201-214. 
King, K. B. (1997). Psychological and social aspects of cardiovascular disease. Annals of Behavioral Medicine, 19, 264-270.

Krantz, D. S., \& Manuck, S. B. (1984). Acute psychophysiological reactivity and risk for cardiovascular disease: A review and methodological critique. Psychological Bulletin, 96, 435-464.

Lacey, J. I., Bateman, D. E., \& Van Lehn, R. (1953). Autonomic response specificity: An experimental study. Psychosomatic Medicine, 15, 8-21.

Malmo, R. B., Shagass, C., \& Davis, F. H. (1950). Symptom specificity and bodily reactions during psychiatric interview. Psychosomatic Medicine, 12, 362-376.

Manuck, S. B. (1994). Cardiovascular reactivity in cardiovascular disease: "Once more unto the breach." International Journal of Behavioral Medicine, 1, 4-31.

Manuck, S. B., Kaplan, J. R., Adams, M. R., \& Clarkson, T. B. (1989). Behaviorally elicited heart rate reactivity and atherosclerosis in female cynomolgus monkeys (Mascaca fascisularis). Psychosomatic Medicine, 51, 306-318.

Manuck, S. B., Kaplan, J. R., \& Clarkson, T. B. (1983). Social instability and coronary artery atherosclerosis in cynomolgus monkeys. Neuroscience and Biobehavioral Reviews, 7 , 485-491.

Manuck, S. B., Kasprowicz, A. L., Monroe, S. B., Larkin, K. T., \& Kaplan, J. R. (1989). Psychophysiologic reactivity as a dimension of individual differences. In N. Schneiderman, S. B. Weiss, \& P. Kaufmann (Eds.), Handbook of methods and measurements in cardiovascular behavioral medicine (pp.365-382). New York: Plenum.

Marler, M. R., Jacob, R. G., Lehoczky, J. P., \& Shapiro, A. P. (1988). The statistical analysis of treatment effects in 24-hour ambulatory blood pressure recordings. Statistics in Medicine, 7, 697-716.

Matthews, K. A., \& Haynes, S. G. (1986). Type A behavior pattern and coronary disease risk: Update and critical evaluation. American Journal of Epidemiology, 123, 923-960.

Matthews, K. A., \& Stoney, C. M. (1988). Influences of sex and age on cardiovascular responses during stress. Psychosomatic Medicine, 50, 46-56.

Menkes, M. S., Matthews, K. A., Krantz, D. S., Lundberg, U., Mead, L. A., Qaquish, B., Liang, K. Y., Thomas, C. B., \& Pearson, T. A. (1989). Cardiovascular reactivity to the cold pressor test as a predictor or hypertension. Hypertension, 14, 524-530.

Moos, R. H., \& Engel, B. T. (1962). Psychophysiological reactions in hypertensive and arthritic patients. Journal of Psychosomatic Research, 6, 227-241. 
Orth-Gomer, K. (1994). International epidemiological evidence for a relationship between social support and cardiovascular disease. In S. A. Shumaker \& S. M. Czajkowski (Eds.), Social support and cardiovascular disease (pp. 97-117). New York: Plenum.

Pearson, G. L., \& Freeman, F. G. (1991). Effects of extraversion and mental arithmetic on heart rate reactivity. Perceptual and Motor Skills, 72, 1239-1248.

Ruberman, W., Weinblatt, E., Goldberg, J., \& Chaudhary, B. S. (1984). Psychosocial influences on mortality after myocardial infarction. New England Journal of Medicine, 311, 552559.

Shapiro, D., Goldstein, I. B., \& Jamner, L. D. (1995). Effects of anger/hostility, defensiveness, gender, and family history of hypertension on cardiovascular reactivity. Psychophysiology, 32, 425-435.

Siegel, J. M. (1984). Anger and cardiovascular risk in adolescents. Health Psychology, 3, 293313.

Stone, S. V., Dembroski, T. M., Costa, P. T., \& MacDougall, J. M. (1990). Gender differences in cardiovascular reactivity. Journal of Behavioral Medicine, 13, 137-156.

Stoney, C. M., Davis, M. C., \& Matthews, K. A. (1987). Sex differences in physiological responses to stress and in coronary heart disease: A causal link? Psychophysiology, 24, 393-402.

Vogele, C., Jarvis, A., \& Cheeseman, K. (1997). Anger suppression, reactivity, and hypertension risk: Gender makes a difference. Annals of Behavioral Medicine, 19, 61-69. 


\section{Table 1}

Means (and Standard Deviations) for Male and Female Extraverts and Introverts by Extraversion $\underline{\text { Measure }}$

\begin{tabular}{|c|c|c|c|c|c|c|}
\hline \multirow[b]{2}{*}{ Measures of Extraversion } & \multicolumn{2}{|c|}{ Male $^{\mathrm{a}}$} & \multicolumn{2}{|c|}{ Female $^{\mathrm{a}}$} & \multicolumn{2}{|c|}{ Total $^{\mathrm{b}}$} \\
\hline & $\underline{\mathrm{M}}$ & $(\underline{\mathrm{SD}})$ & $\underline{\mathrm{M}}$ & $(\underline{\mathrm{SD}})$ & $\underline{\mathrm{M}}$ & $(\underline{\mathrm{SD}})$ \\
\hline & \multicolumn{6}{|c|}{ Extraverts } \\
\hline EPI Total Score ${ }^{\mathrm{e}}$ & 22.50 & $(1.59)$ & 22.56 & $(2.19)$ & 22.53 & $(1.88)$ \\
\hline Nights “Out” per Week c,d & 2.75 & $(1.77)$ & 2.00 & $(1.15)$ & 2.38 & $(1.52)$ \\
\hline Nights at Library per Week ${ }^{\mathrm{d}}$ & 0.25 & $(0.58)$ & 0.63 & $(1.07)$ & 0.44 & $(0.87)$ \\
\hline \multirow[t]{2}{*}{ Considered Extravert ${ }^{\mathrm{e}}$} & 13 & $(81.3 \%)$ & 15 & $(93.8 \%)$ & 28 & $(87.5 \%)$ \\
\hline & \multicolumn{6}{|c|}{ Introverts } \\
\hline EPI Total Score ${ }^{e}$ & 10.06 & $(2.54)$ & 8.06 & $(2.46)$ & 9.06 & $(2.66)$ \\
\hline Nights “Out" per Week ${ }^{c, d}$ & 1.94 & $(1.05)$ & 0.96 & $(0.74)$ & 1.45 & $(1.02)$ \\
\hline Nights at Library per Week ${ }^{d}$ & 1.27 & $(1.82)$ & 1.44 & $(1.63)$ & 1.35 & $(1.70)$ \\
\hline Considered Extravert ${ }^{\mathrm{e}}$ & 9 & $(56.3 \%)$ & 12 & $(75.0 \%)$ & 21 & $(65.6 \%)$ \\
\hline
\end{tabular}

Note. Self-report of whether the participants considered themselves to be an extravert or an introvert are reported as frequencies and percentages.

${ }^{\mathrm{a}} \underline{\mathrm{n}}=16 .{ }^{\mathrm{b}} \underline{\mathrm{n}}=32 .{ }^{\mathrm{c}}$ Males greater than females, $\underline{\mathrm{p}}<.01 .{ }^{\mathrm{d}}$ Extraverts greater than introverts, $\underline{\mathrm{p}}<.01$. ${ }^{\mathrm{e}}$ Extraverts greater than introverts, $\mathrm{p}<.001$. 


\section{Table 2}

$\underline{\text { Parametric Characteristics of Extraverts as a Function of Gender }}$

\begin{tabular}{|c|c|c|c|c|c|c|c|c|c|}
\hline \multirow[b]{2}{*}{ Characteristic } & \multicolumn{3}{|c|}{ Male } & \multicolumn{3}{|c|}{ Female } & \multicolumn{3}{|c|}{ Total } \\
\hline & $\underline{\mathrm{M}}$ & $(\underline{\mathrm{SD}})$ & $\underline{\mathrm{n}}$ & $\underline{\mathrm{M}}$ & $(\underline{\mathrm{SD}})$ & $\underline{\mathrm{n}}$ & $\underline{\mathrm{M}}$ & $(\underline{\mathrm{SD}})$ & $\underline{\mathrm{n}}$ \\
\hline Age & 22.13 & $(6.20)$ & 16 & 19.88 & $(1.63)$ & 16 & 21.00 & $(4.60)$ & 32 \\
\hline Height (Inches) ${ }^{\mathrm{a}}$ & 71.81 & $(2.71)$ & 16 & 65.31 & $(2.67)$ & 16 & 68.56 & $(4.23)$ & 32 \\
\hline Weight (Pounds) ${ }^{a}$ & 177.38 & $(25.13)$ & 16 & 135.25 & $(17.89)$ & 16 & 156.31 & $(30.31)$ & 32 \\
\hline Body Mass Index (BMI) & 24.27 & $(3.29)$ & 16 & 22.37 & $(2.74)$ & 16 & 23.32 & $(3.13)$ & 32 \\
\hline Higher Education Completed (Yrs) & 2.13 & $(1.41)$ & 16 & 1.88 & $(1.63)$ & 16 & 2.00 & $(1.50)$ & 32 \\
\hline Monthly Exercise (Hrs) & 26.92 & $(15.23)$ & 13 & 24.87 & $(16.34)$ & 14 & 25.86 & $(15.55)$ & 27 \\
\hline Monthly Tobacco Use (\# cigarettes) & 415.00 & $(240.30)$ & 7 & 425.00 & $(247.49)$ & 2 & 417.22 & $(225.79)$ & 9 \\
\hline Monthly Alcohol Use a,b (\# drinks) & 112.18 & $(63.16)$ & 14 & 47.91 & $(49.33)$ & 14 & 80.04 & $(64.53)$ & 28 \\
\hline Monthly Recreational Drugs (\# uses) & 16.75 & $(14.22)$ & 4 & 24.75 & $(32.88)$ & 2 & 19.42 & $(18.83)$ & 6 \\
\hline
\end{tabular}

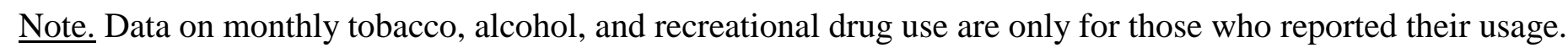

${ }^{\mathrm{a}}$ Males greater than females, $\mathrm{p}<.01 .{ }^{\mathrm{b}}$ Extraverts greater than introverts, $\mathrm{p}<.03$. 


\section{Table 3}

$\underline{\text { Parametric Characteristics of Introverts as a Function of Gender }}$

\begin{tabular}{|c|c|c|c|c|c|c|c|c|c|}
\hline \multirow[b]{2}{*}{ Characteristic } & \multicolumn{3}{|c|}{ Male } & \multicolumn{3}{|c|}{ Female } & \multicolumn{3}{|c|}{ Total } \\
\hline & $\underline{\mathrm{M}}$ & $(\underline{\mathrm{SD}})$ & $\underline{\mathrm{n}}$ & $\underline{\mathrm{M}}$ & $(\underline{\mathrm{SD}})$ & $\underline{\mathrm{n}}$ & $\underline{\mathrm{M}}$ & $(\underline{\mathrm{SD}})$ & $\underline{\mathrm{n}}$ \\
\hline Age & 21.56 & $(5.23)$ & 16 & 21.00 & $(4.56)$ & 16 & 21.28 & $(4.83)$ & 32 \\
\hline Height (Inches) $^{a}$ & 71.17 & $(2.49)$ & 16 & 65.28 & $(3.14)$ & 16 & 68.23 & $(4.09)$ & 32 \\
\hline Weight (Pounds) ${ }^{a}$ & 184.94 & $(35.50)$ & 16 & 145.73 & $(44.59)$ & 15 & 165.97 & $(44.21)$ & 31 \\
\hline Body Mass Index (BMI) & 25.66 & $(4.33)$ & 16 & 23.85 & $(7.47)$ & 15 & 24.78 & $(6.02)$ & 31 \\
\hline Higher Education Completed (Yrs) & 1.63 & $(1.71)$ & 16 & 1.69 & $(1.49)$ & 16 & 1.66 & $(1.58)$ & 32 \\
\hline Monthly Exercise (Hrs) & 27.45 & $(14.09)$ & 8 & 19.23 & $(12.35)$ & 11 & 22.69 & (13.39) & 19 \\
\hline Monthly Tobacco Use (\# cigarettes) & 285.00 & $(148.49)$ & 2 & 251.50 & $(68.59)$ & 2 & 268.25 & $(96.40)$ & 4 \\
\hline Monthly Alcohol Use a,b (\# drinks) & 52.89 & $(58.66)$ & 7 & 24.43 & $(15.22)$ & 7 & 38.66 & $(43.74)$ & 14 \\
\hline Monthly Recreational Drugs (\# uses) & 0 & $(0)$ & 0 & 13.00 & $(16.97)$ & 2 & 13.00 & (16.97) & 2 \\
\hline
\end{tabular}

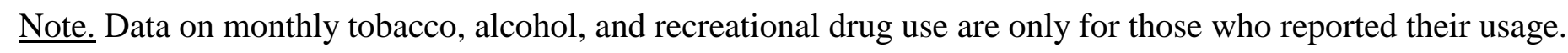

${ }^{\mathrm{a}}$ Males greater than females, $\mathrm{p}<.01 .{ }^{\mathrm{b}}$ Extraverts greater than introverts, $\mathrm{p}<.03$. 
Table 4

Non-Parametric Characteristics as a Function of Gender and Extraversion Classification

\begin{tabular}{|c|c|c|c|c|c|c|}
\hline \multirow[b]{2}{*}{ Characteristic } & \multicolumn{2}{|c|}{ Male } & \multicolumn{2}{|c|}{ Female } & \multicolumn{2}{|c|}{ Total } \\
\hline & $\underline{\text { Freq }}$ & $(\%)$ & Freq & $(\%)$ & Freq & $(\%)$ \\
\hline & \multicolumn{6}{|c|}{ Extraverts } \\
\hline Race (Caucasian) & 16 & $(100)$ & 16 & $(100)$ & 32 & $(100)$ \\
\hline Marital Status (Single) & 14 & $(87.5)$ & 15 & $(93.8)$ & 29 & $(90.6)$ \\
\hline Chronic Medical Condition (Yes) & 0 & $(0)$ & 2 & $(12.5)$ & 2 & $(6.25)$ \\
\hline Family History of CVD (Yes) & 2 & $(12.5)$ & 4 & $(25)$ & 6 & $(18.8)$ \\
\hline Current Med Usage (Yes) ${ }^{\mathrm{a}}$ & 2 & $(12.5)$ & 2 & $(12.5)$ & 4 & $(12.5)$ \\
\hline Current Exercise (Yes) ${ }^{b}$ & 13 & $(81.3)$ & 14 & $(87.5)$ & 27 & $(84.4)$ \\
\hline Current Tobacco Use (Yes) & 7 & $(43.8)$ & 2 & $(12.5)$ & 9 & $(28.1)$ \\
\hline Current Alcohol Use (Yes) ${ }^{d}$ & 14 & $(87.5)$ & 15 & $(93.8)$ & 29 & $(90.6)$ \\
\hline \multirow[t]{2}{*}{ Current Recreational Drugs (Yes) ${ }^{c}$} & 8 & $(50)$ & 3 & $(18.8)$ & 11 & $(34.4)$ \\
\hline & \multicolumn{6}{|c|}{ Introverts } \\
\hline Race (Caucasian) & 15 & $(93.8)$ & 11 & $(68.8)$ & 26 & $(81.3)$ \\
\hline Marital Status (Single) & 13 & $(81.3)$ & 12 & (75) & 25 & $(78.1)$ \\
\hline Chronic Medical Condition (Yes) & 1 & $(6.3)$ & 0 & $(0)$ & 1 & $(3.1)$ \\
\hline Family History of CVD (Yes) & 3 & $(18.8)$ & 4 & (25) & 7 & $(21.9)$ \\
\hline Current Med Usage (Yes) ${ }^{a}$ & 1 & $(6.3)$ & 8 & $(50)$ & 9 & $(28.1)$ \\
\hline Current Exercise (Yes) ${ }^{b}$ & 9 & $(56.3)$ & 11 & $(68.8)$ & 20 & $(62.5)$ \\
\hline Current Tobacco Use (Yes) & 3 & $(18.8)$ & 2 & $(12.5)$ & 5 & $(15.6)$ \\
\hline Current Alcohol Use (Yes) ${ }^{d}$ & 8 & $(50)$ & 8 & $(50)$ & 16 & $(50)$ \\
\hline Current Recreational Drugs (Yes) ${ }^{c}$ & 0 & $(0)$ & 3 & $(18.8)$ & 3 & $(9.4)$ \\
\hline
\end{tabular}

${ }^{\mathrm{a}}$ Females greater than males, $\mathrm{p}=.03$. ${ }^{\mathrm{b}}$ Extraverts greater than introverts, $\mathrm{p}<.05 .{ }^{\mathrm{c}}$ Extraverts greater than introverts, $\mathrm{p}<.02$. ${ }^{\mathrm{d}}$ Extraverts greater than introverts, $\mathrm{p}<.001$. 
Table 5

Mean Heart Rates (bpm) (and Standard Deviations) by Gender and Extraversion Classification

\begin{tabular}{|c|c|c|c|c|c|}
\hline \multirow[b]{2}{*}{ Task } & \multicolumn{2}{|c|}{ Male } & Female & \multicolumn{2}{|c|}{ Total } \\
\hline & $\underline{\mathrm{M}}$ & $(\underline{\mathrm{SD}})$ & $(\underline{\mathrm{SD}})$ & $\underline{\mathrm{M}}$ & $(\underline{\mathrm{SD}})$ \\
\hline & \multicolumn{5}{|c|}{ Extraverts } \\
\hline Pre Non-Social & 76.09 & $(12.90)$ & $78.22 \quad(10.66)$ & 77.16 & (11.69) \\
\hline Non-Social & 81.06 & (12.18) & $85.08 \quad(10.40)$ & 83.07 & (11.33) \\
\hline Pre Social & 74.39 & $(12.49)$ & $77.93 \quad(9.97)$ & 76.16 & (11.26) \\
\hline \multirow[t]{2}{*}{ Social } & 86.83 & $(12.45)$ & $91.50 \quad(10.82)$ & 89.17 & (11.72) \\
\hline & \multicolumn{5}{|c|}{ Introverts } \\
\hline Pre Non-Social & 78.64 & $(15.43)$ & $79.97 \quad(10.34)$ & 79.30 & $(12.94)$ \\
\hline Non-Social & 84.94 & (16.30) & $87.00 \quad(9.99)$ & 85.97 & (13.34) \\
\hline Pre Social & 77.37 & (13.97) & $80.84 \quad(9.64)$ & 79.10 & (11.94) \\
\hline Social & 90.83 & (17.27) & $93.85 \quad(13.23)$ & 92.34 & (15.21) \\
\hline
\end{tabular}


Table 6

Mean Systolic Blood Pressures (mm Hg) (and Standard Deviations) by Gender and Extraversion Classification

\begin{tabular}{|c|c|c|c|}
\hline \multirow[b]{2}{*}{ Task } & Male & Female & Total \\
\hline & $(\underline{\mathrm{SD}})$ & $(\underline{\mathrm{SD}})$ & $(\underline{\mathrm{SD}})$ \\
\hline & \multicolumn{3}{|c|}{ Extraverts } \\
\hline Pre Non-Social & $125.50(7.45)$ & $110.05(8.28)$ & $117.78(11.03)$ \\
\hline Non-Social & $136.03(10.67)$ & $116.97(10.61)$ & $126.50(14.26)$ \\
\hline Pre Social & $123.29(7.24)$ & $109.31(7.10)$ & $116.30(10.01)$ \\
\hline \multirow[t]{2}{*}{ Social } & $146.47(16.88)$ & $127.91(13.51)$ & $137.19(17.75)$ \\
\hline & \multicolumn{3}{|c|}{ Introverts } \\
\hline Pre Non-Social & $124.27(11.43)$ & $111.75(12.89)$ & 118.01 \\
\hline Non-Social & $133.47(14.66)$ & $118.28(15.79)$ & $125.88(16.86)$ \\
\hline Pre Social & $122.25(9.09)$ & $111.02(11.05)$ & $116.64(11.47)$ \\
\hline Social & $147.28(15.18)$ & $126.28(15.52)$ & $136.78(18.49)$ \\
\hline
\end{tabular}


Table 7

Mean Diastolic Blood Pressures (mm Hg) (and Standard Deviations) by Gender and Extraversion Classification

\begin{tabular}{|c|c|c|c|c|c|}
\hline \multirow[b]{2}{*}{ Task } & \multicolumn{2}{|c|}{ Male } & Female & \multicolumn{2}{|c|}{ Total } \\
\hline & $\underline{\mathrm{M}}$ & $(\underline{\mathrm{SD}})$ & $(\underline{\mathrm{SD}})$ & $\underline{\mathrm{M}}$ & $(\underline{\mathrm{SD}})$ \\
\hline & \multicolumn{5}{|c|}{ Extraverts } \\
\hline Pre Non-Social & 72.06 & $(7.45)$ & $67.52(8.25)$ & 69.79 & $(8.07)$ \\
\hline Non-Social & 83.38 & $(9.94)$ & $76.31 \quad(9.05)$ & 79.84 & $(10.01)$ \\
\hline Pre Social & 71.33 & $(9.01)$ & $67.38 \quad(9.03)$ & 69.35 & $(9.10)$ \\
\hline \multirow[t]{2}{*}{ Social } & 83.81 & $(12.75)$ & 79.63 (9.80) & 81.72 & (11.39) \\
\hline & \multicolumn{5}{|c|}{ Introverts } \\
\hline Pre Non-Social & 69.92 & $(10.46)$ & $71.60 \quad(8.58)$ & 70.76 & $(9.45)$ \\
\hline Non-Social & 80.28 & $(9.67)$ & $79.44 \quad(8.65)$ & 79.86 & $(9.03)$ \\
\hline Pre Social & 68.83 & $(10.00)$ & $72.06 \quad(6.31)$ & 70.45 & $(8.38)$ \\
\hline Social & 83.31 & $(12.10)$ & $84.81 \quad(8.38)$ & 84.06 & $(10.27)$ \\
\hline
\end{tabular}


Table 8

Mean SUDS Ratings (and Standard Deviations) by Gender and Extraversion Classification

\begin{tabular}{|c|c|c|c|c|c|c|}
\hline \multirow[b]{2}{*}{ Task } & \multicolumn{2}{|c|}{ Male } & \multicolumn{2}{|c|}{ Female } & \multicolumn{2}{|c|}{ Total } \\
\hline & $\underline{\mathrm{M}}$ & $(\underline{\mathrm{SD}})$ & $\underline{\mathrm{M}}$ & $(\underline{\mathrm{SD}})$ & $\underline{\mathrm{M}}$ & $(\underline{\mathrm{SD}})$ \\
\hline & \multicolumn{6}{|c|}{ Extraverts } \\
\hline Pre Non-Social & 0.81 & $(0.91)$ & 0.94 & $(1.18)$ & 0.88 & $(1.04)$ \\
\hline Non-Social & 1.56 & $(1.41)$ & 1.81 & $(1.52)$ & 1.69 & $(1.45)$ \\
\hline Pre Social & 1.00 & $(1.10)$ & 1.31 & $(1.70)$ & 1.16 & $(1.42)$ \\
\hline \multirow[t]{2}{*}{ Social } & 4.31 & $(2.41)$ & 4.69 & $(2.06)$ & 4.50 & $(2.21)$ \\
\hline & \multicolumn{6}{|c|}{ Introverts } \\
\hline Pre Non-Social & 1.31 & $(1.96)$ & 1.13 & $(1.36)$ & 1.22 & $(1.66)$ \\
\hline Non-Social & 2.25 & $(2.18)$ & 1.25 & (1.24) & 1.75 & $(1.81)$ \\
\hline Pre Social & 1.13 & $(1.93)$ & 1.00 & $(1.21)$ & 1.06 & $(1.58)$ \\
\hline Social & 4.75 & $(2.27)$ & 5.56 & $(2.58)$ & 5.16 & $(2.42)$ \\
\hline
\end{tabular}


Table 9

Means (and Standard Deviations) of Cardiovascular Reactivity Measures Across Tasks and $\underline{\text { Studies }}$

\begin{tabular}{|c|c|c|c|c|c|}
\hline \multirow[b]{2}{*}{ Task } & \multicolumn{2}{|c|}{ Present } & \multicolumn{2}{|c|}{ Davig et al. } & Frazer et al. \\
\hline & $\underline{\mathrm{M}}$ & $(\underline{\mathrm{SD}})$ & $\underline{\mathrm{M}}$ & $(\underline{\mathrm{SD})}$ & $(\underline{\mathrm{SD}})$ \\
\hline \multicolumn{6}{|l|}{ Heart Rate (bpm) } \\
\hline Resting & 77.98 & $(12.39)$ & 67.76 & $(10.81)$ & \\
\hline Non-Social Task & 84.52 & $(12.36)$ & 76.66 & $(12.97)$ & $88.34 \quad(11.32)$ \\
\hline Social Task & 90.76 & $(13.56)$ & 84.70 & $(14.01)$ & $87.47 \quad(10.32)$ \\
\hline \multicolumn{6}{|l|}{$\mathrm{SBP}(\mathrm{mm} \mathrm{Hg})$} \\
\hline Resting & 116.26 & $(11.26)$ & 118.1 & $(9.16)$ & \\
\hline Non-Social Task & 126.19 & $(15.49)$ & 125.0 & $(10.15)$ & $135.57(9.53)$ \\
\hline Social Task & 136.98 & $3(17.98)$ & 132.4 & (12.08) & $138.64(9.91)$ \\
\hline \multicolumn{6}{|l|}{ DBP (mm Hg) } \\
\hline Resting & 68.67 & $(8.63)$ & 71.73 & $(8.37)$ & \\
\hline Non-Social Task & 79.85 & $(9.46)$ & 75.73 & $(6.73)$ & $89.43 \quad(7.49)$ \\
\hline Social Task & 82.89 & $(10.82)$ & 79.95 & $(7.48)$ & $91.01 \quad(9.91)$ \\
\hline
\end{tabular}


Appendix A

\section{Demographic Information}

Name (Print):

Phone Number:

1) Please indicate your sex:

Email:

O Male

O Female

2) Please indicate your age:

3) Please indicate your birthdate:

4) Please indicate your height: feet inches

5) Please indicate your weight: lbs

6) Please indicate your race:
O African American
O Caucasian
O Hispanic
O Asian / Pacific Islander
$\mathrm{O}$ Other

7) Please indicate your marital status:
O Single
O Cohabiting/ Live-In Partner
O Married
O Divorced / Separated

8) Total Number Years of Education Completed:

O High school

O 1 year college

O 2 years college

O 3 years college

O 4 or more years college

9) Do you have any chronic medical conditions $\quad$ Yes No (e.g., hypertension, heart disease, diabetes, asthma, etc...)?

If yes, explain:

10) Do you have a history of hypertension, coronary heart disease Yes No or strokes in your family?

What (Who): 
11) Are you taking any medications on a regular basis? $\quad$ Yes No

If yes, explain:

12) Do you currently exercise? $\quad$ Yes No

What?

How frequently? (i.e., how many days per month)

How much per episode? (e.g., hours per day)

13) Do you currently use tobacco?

Yes No

(e.g. smoke cigarettes, cigars or chew tobacco)

What?

How frequently? (i.e., how many days per month)

How much per episode? (e.g., packs per day)

Last time? (e.g., days ago)

14) Do you drink alcohol?

Yes No

What?

How frequently? (i.e., how many days per month)

How much per episode? (e.g., cans, glasses, shots)

Last time? (e.g., days ago)

15) Do you use any recreational or street drugs?

Yes No

(e.g., marijuana, crack, cocaine, heroine)

What?

How frequently? (i.e., how many days per month)

How much per episode?

Last time? (e.g., days ago)

16) How many nights per week do you typically "go out"?

17) How many nights per week do you typically go to the library?

18) Do you consider yourself to be more of an: (circle one) Extravert or Introvert ? 


\section{Appendix B}

\section{EPI}

Instructions: Here are some questions regarding the way you behave, feel, and act. After each question is a space for answering "Yes," or "No." Try and decide whether "Yes," or "No" represents your usual way of acting or feeling. Then circle the answer you choose.

Work quickly, and don't spend too much time over any question: we want your first reaction, not a long drawn-out thought process. The whole questionnaire shouldn't take more than a few minutes. Be sure not to omit any questions. Work quickly, and remember to answer every question. There are no right or wrong answers, and this isn't a test of intelligence or ability, but simply a measure of the way you behave.

\begin{tabular}{|c|c|c|}
\hline Yes & No & 1. Do you often long for excitement? \\
\hline Yes & No & 2. Are you usually carefree? \\
\hline Yes & No & 3. Do you stop and think things over before doing \\
\hline & & anything? \\
\hline Yes & No & 4. If you say you will do something do you always keep \\
\hline & & $\begin{array}{l}\text { your promise, no matter how inconvenient it might be to do } \\
\text { so? }\end{array}$ \\
\hline Yes & No & 5. Do you generally do and say things quickly without \\
\hline & & stopping to think? \\
\hline Yes & No & 6. Would you do almost anything for a dare? \\
\hline Yes & No & 7. Do you suddenly feel shy when you want to talk to an \\
\hline & & attractive stranger? \\
\hline Yes & No & 8. Once in a while do you lose your temper? \\
\hline Yes & No & 9. Do you often do things on the spur of the moment? \\
\hline Yes & No & 10. Generally do you prefer reading to meeting people? \\
\hline Yes & No & 11. Do you like going out a lot? \\
\hline Yes & No & 12. Do you prefer to have few but special friends? \\
\hline Yes & No & 13. When people shout at you, do you shout back? \\
\hline Yes & No & 14. Can you usually let yourself go and enjoy yourself a lot \\
\hline & & at a party? \\
\hline Yes & No & 15. Would you call yourself tense or "highly-strung?" \\
\hline Yes & No & 16. Do other people think of you as being lively? \\
\hline Yes & No & 17. Are you mostly quiet when you are with other people? \\
\hline Yes & No & 18. Do you sometimes gossip? \\
\hline Yes & No & 19. If there is something you want to know about, would \\
\hline & & $\begin{array}{l}\text { you rather look it up in a book than talk to someone about } \\
\text { it? }\end{array}$ \\
\hline Yes & No & 20. Do you like the kind of work that you need to pay close \\
\hline & & Attention to? \\
\hline Y & No & 21. Do you hate being with a crowd who play jokes on one \\
\hline
\end{tabular}




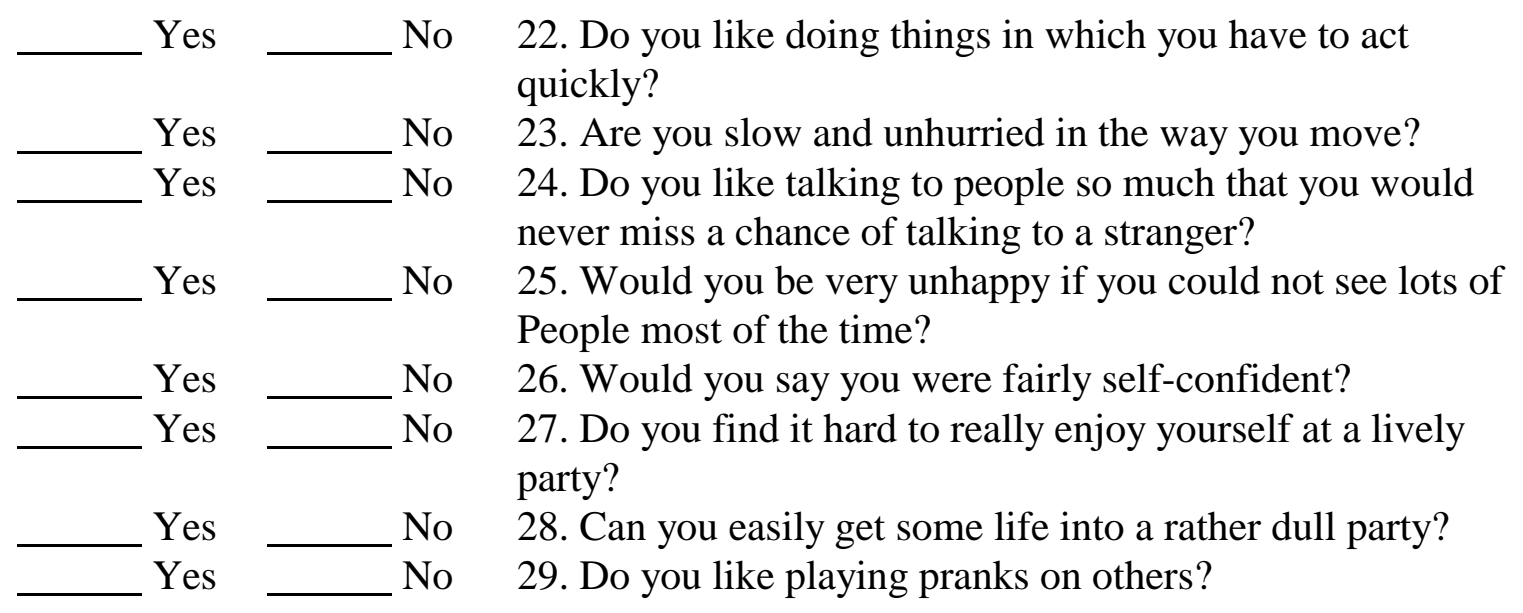




\section{Appendix C}

\section{SUDS}

Please rate on a scale of 0 to 10 how distressed you felt during the previous task.

$\begin{array}{ccccccccccc}0 & 1 & 2 & 3 & 4 & 5 & 6 & 7 & 8 & 9 & \begin{array}{c}10 \\ \text { (Least Distress) }\end{array} \\ & & & & & & & & \end{array}$




\section{Appendix D}

ANCOVA Summary Table:

Heart Rate Adjusted by Pre-Task Rest Period Heart Rate

$\begin{array}{llllll}\text { Source } & \begin{array}{l}\text { Sum of } \\ \text { Squares }\end{array} & \text { df } & \begin{array}{l}\text { Mean } \\ \text { Square }\end{array} & \text { F } & \text { Sig. } \\ \text { GENDER } & 39.75 & 1 & 39.75 & 0.45 & .505 \\ \text { EPI CLASS } & 19.24 & 1 & 19.24 & 0.22 & .642 \\ \text { GENDER * EPICLASS } & 16.21 & 1 & 16.21 & 0.18 & .670 \\ \text { Error } & 5204.75 & 59 & 88.22 & & \\ & & & & & \\ \text { TASK } & 1349.86 & 1 & 1349.86 & 45.84 & .000 \\ \text { GENDER * TASK } & 0.40 & 1 & 0.40 & 0.01 & .907 \\ \text { EPICLASS * TASK } & 0.27 & 1 & 0.27 & 0.01 & .924 \\ \text { GENDER * EPICLASS * TASK } & 0.02 & 1 & 0.02 & 0.00 & .977 \\ \text { Error } & 1737.21 & 59 & 29.44 & & \end{array}$




\section{Appendix E}

ANCOVA Summary Table:

Systolic Blood Pressure Adjusted by Pre-Task Rest Period Systolic Blood Pressure

$\begin{array}{llllll}\text { Source } & \begin{array}{l}\text { Sum of } \\ \text { Squares }\end{array} & \text { df } & \begin{array}{l}\text { Mean } \\ \text { Square }\end{array} & \text { F } & \text { Sig. } \\ \text { GENDER } & 167.69 & 1 & 167.69 & 1.30 & .258 \\ \text { EPI CLASS } & 23.05 & 1 & 23.05 & 0.18 & .674 \\ \text { GENDER * EPICLASS } & 54.31 & 1 & 54.31 & 0.42 & .518 \\ \text { Error } & 7585.47 & 59 & 128.57 & & \\ & & & & & \\ \text { TASK } & 3407.87 & 1 & 3407.87 & 78.37 & .000 \\ \text { GENDER * TASK } & 59.26 & 1 & 59.26 & 1.36 & .248 \\ \text { EPICLASS * TASK } & 0.36 & 1 & 0.36 & 0.01 & .928 \\ \text { GENDER * EPICLASS * TASK } & 79.36 & 1 & 79.36 & 1.82 & .182 \\ \text { Error } & 2565.58 & 59 & 43.48 & & \end{array}$




\section{Appendix F}

ANCOVA Summary Table:

Diastolic Blood Pressure Adjusted by Pre-Task Rest Period Diastolic Blood Pressure

$\begin{array}{llllll}\text { Source } & \begin{array}{l}\text { Sum of } \\ \text { Squares }\end{array} & \text { df } & \begin{array}{l}\text { Mean } \\ \text { Square }\end{array} & \text { F } & \text { Sig. } \\ \text { GENDER } & 123.55 & 1 & 123.55 & 1.55 & .218 \\ \text { EPI CLASS } & 5.01 & 1 & 5.01 & 0.06 & .803 \\ \text { GENDER * EPICLASS } & 5.64 & 1 & 5.64 & 0.07 & .791 \\ \text { Error } & 4692.63 & 59 & 79.54 & & \\ & & & & & \\ \text { TASK } & 290.86 & 1 & 290.86 & 5.46 & .023 \\ \text { GENDER * TASK } & 56.34 & 1 & 56.34 & 1.06 & .308 \\ \text { EPICLASS * TASK } & 43.59 & 1 & 43.59 & 0.82 & .369 \\ \text { GENDER * EPICLASS * TASK } & 0.47 & 1 & 0.47 & 0.01 & .926 \\ \text { Error } & 3140.39 & 59 & 53.23 & & \end{array}$




$$
\begin{gathered}
\text { Appendix G } \\
\text { ANCOVA Summary Table: } \\
\text { Subjective Units of Distress Ratings Adjusted by } \\
\text { Pre-Task Rest Period Subjective Units of Distress Ratings }
\end{gathered}
$$

$\begin{array}{llllll}\text { Source } & \begin{array}{l}\text { Sum of } \\ \text { Squares }\end{array} & \text { df } & \begin{array}{l}\text { Mean } \\ \text { Square }\end{array} & \text { F } & \text { Sig. } \\ \text { GENDER } & 0.24 & 1 & 0.24 & 0.06 & .802 \\ \text { EPI CLASS } & 2.28 & 1 & 2.28 & 0.61 & .440 \\ \text { GENDER * EPICLASS } & 0.13 & 1 & 0.13 & 0.04 & .851 \\ \text { Error } & 222.25 & 59 & 3.77 & & \\ \text { TASK } & & & & & \\ \text { GENDER * TASK } & 303.01 & 1 & 303.01 & 135.77 & .000 \\ \text { EPICLASS * TASK } & 6.79 & 1 & 6.79 & 3.04 & .086 \\ \text { GENDER * EPICLASS * TASK } & 4.16 & 1 & 4.16 & 1.86 & .177 \\ \text { Error } & 13.99 & 1 & 5.99 & 2.68 & .107 \\ & & 59 & 2.23 & & \end{array}$




\section{BRANDIE K. TAYLOR}

CURRICULUM VITAE

\begin{tabular}{|c|c|c|c|}
\hline Mailing Address: & $\begin{array}{l}1293 \text { Van Voorhis Road } \\
\text { Apt. C } \\
\text { Morgantown, WV } 26505\end{array}$ & School Address: & $\begin{array}{l}\text { P.O. Box } 6040 \\
\text { Department of Psychology } \\
\text { West Virginia University } \\
\text { Morgantown, WV } 26506\end{array}$ \\
\hline $\begin{array}{l}\text { Home Telephone: } \\
\text { E-Mail: }\end{array}$ & $\begin{array}{l}\text { (304) 599-0664 } \\
\text { bktavlor95@ @otmail.com }\end{array}$ & $\begin{array}{l}\text { School Telephone: } \\
\text { School Fax: }\end{array}$ & $\begin{array}{l}\text { (304) 293-2001 x804 } \\
\text { (304) 293-6606 }\end{array}$ \\
\hline
\end{tabular}

\section{EDUCATION}

Candidate, Doctor of Philosophy in Clinical Psychology

West Virginia University, Morgantown, West Virginia 26506

Specialization: Behavioral Medicine

* Earned and paid for $100 \%$ of college expenses

Candidate, Master of Arts in Clinical Psychology

West Virginia University, Morgantown, West Virginia 26506

Master's Thesis: Potential Relations Between Extraversion and

Cardiovascular Reactivity to Laboratory Stressors

* Earned and paid for $100 \%$ of college expenses

Bachelor of Arts in Psychology, Summa cum laude

Ohio University, Honors Tutorial College, Athens, Ohio 45701

Minors: Biological Sciences \& Political Science

Honors Thesis: Using Psychological Measures to Predict Vasovagal

Reactions in Volunteer Blood Donors

*Earned and paid for $100 \%$ of college expenses

High School Honors Diploma

Union Local High School, Belmont, Ohio 43718

*Valedictorian

\section{ACADEMIC HONOR SOCIETIES}

Phi Beta Kappa National Honor Society

Phi Kappa Phi National Honor Society

Pi Gamma Mu International Social Science Honor Society

Golden Key National Honor Society

*President (Elected Two Consecutive Years)
1998

1998

1998

1998

1997

May 2004

(Anticipated)

December 2001

June 1999

June 1995

1997,1998 


\section{SCHOLARSHIPS}

HERF Fellowship

1999

1999

1999

Ohio Board of Regents Fellowship Nominee

1998

1998

1997, 1998

1996, 1997, 1998

1995

1995

1995-1999

Ohio Academic Scholarship (Four Year Award)

\section{RESEARCH EXPERIENCE}

\section{Graduate Research Assistant: Isolated White Coat Normotensive (ICN) Project $\quad$ June 2001- Present Wellness Office, Health Sciences Center West Virginia University, Morgantown, WV \\ Aiding in organization, communication among research team members, scheduling and running research participants, data entry and analyses, etc. for a multidisciplinary research project designed to examine the relation between normotensive, hypertensive, and ICN patients on several indices of cardiovascular health. Supervisor: Kevin T. Larkin, Ph.D.}

\section{Graduate Research Assistant: Yoga Therapy for Low Back Pain Project $\quad$ Nov 2000-June 2001 Wellness Office, Health Sciences Center West Virginia University, Morgantown, WV \\ Aided in grant writing, IRB writing and approval, organization, communication among research team members, data analyses, etc. for a multidisciplinary research project designed to examine the effects of a yoga therapy intervention on patients with chronic mechanical low back pain. \\ Supervisor: Kimberly Williams, Ph.D.}

\section{Graduate Research Assistant: Child Health and Medical Procedures Laboratory Aug 2000-Present West Virginia University, Morgantown, WV \\ Pediatric psychology research examining pain, distress, and coping in children undergoing painful medical procedures (e.g., immunizations, venipunctures). Duties include: coding, data entry, statistical analysis, editing manuscripts, IRB writing and approval, preparing data for presentation, etc. \\ Supervisor: Lindsey L. Cohen, Ph.D.}

Master's Thesis

West Virginia University, Morgantown, WV

Aug 2000-Dec 2001

Potential Relations Between Extraversion and Cardiovascular Reactivity to Laboratory Stressors This study is designed to examine the effects of a social and non-social laboratory stressor on cardiovascular reactivity with individuals who are identified as either "introverts" or "extraverts." Project Supervisors: Kevin T. Larkin, Ph.D.; Stan Cohen, Ph.D.; Lindsey L. Cohen, Ph.D. 
Graduate Research Assistant: Mental Stress-Induced Ischemia Project

July 2000-June 2001

Wellness Office, Health Sciences Center

West Virginia University, Morgantown, WV

Coordinated multidisciplinary research project and research team examining the effects of mental stressinduced ischemia on the heart, cardiovascular reactivity, and blood cortisol and catecholamine levels of patients with documented coronary artery disease. Aided in all phases of the study, maintained communication among all members of the research team and referring physicians, coordinated research team meetings, evaluated and refined study protocols, helped write, organize, and amend IRB approval and other necessary forms, interviewed, ran, and scheduled participants, etc.

Supervisor: Kimberly Williams, Ph.D.

Co-Investigator: Anxiety and Cardiovascular Reactivity to Laboratory Stressors $\quad$ Aug 1999-Dec 2000 West Virginia University, Morgantown, WV

Aided in data collection and data entry for study designed to examine the relation of anxiety symptomology and cardiovascular reactivity to stress.

Supervisor: Kevin T. Larkin, Ph.D.

Research Apprentice: Psychophysiology Laboratory

Sept 1998-June 1999

Ohio University, Athens, Ohio

Trained and involved in all phases of a study designed to research and refine interventions to reduce blood donor distress and enhance current levels of donor retention. Organized and conducted several experimental sessions. Scored and entered several questionnaires and experimental data.

Supervisor: Christopher France, Ph.D.

\section{Research Assistant: Project Uplift, Fibromyalgia Laboratory} Ohio University, Athens, Ohio

Received training in the experimental study of fibromyalgia treatment. Conducted telephone screening interviews and recruitment of potential participants. Scheduled appointments, made reminder and courtesy calls and was responsible for organizing and entering incoming data.

Laboratory Director: Francis Keefe, Ph.D.

Honors Thesis

Ohio University, Athens, Ohio

Sept 1997-July 1998

Using Psychological Measures to Predict Vasovagal Reactions in Volunteer Blood Donors

The utility of the Medical Fear Survey (MFS) as a predictor of vasovagal reactions to blood donation was assessed with the assistance of 364 volunteer blood donors. Participants completed the MFS prior to the donation process and the Blood Donation Reactions Inventory (BDRI) following donation. With some variation, correlations were found between MFS scores and BDRI scores for all groups. Additionally, correlations were observed between MFS and BDRI scores and likelihood of future donation. A hierarchical regression analysis conducted to examine the contributions of donation experience, gender, and the three subscales of the MFS to the explanation of variability in BDRI scores concluded that only the hypodermic injections and blood draws subscale of the MFS was a significant predictor of BDRI scores. This ability of the MFS to predict vasovagal reactions in volunteer blood donors offers tremendous potential to blood centers and blood donors alike. With the ability to identify high-risk donors, preventive measures could be initiated to decrease donor reaction rates and increase donor retention rates.

Project Supervisors: Christopher France, Ph.D.; Timothy Anderson, Ph.D.; Julie Suhr, Ph.D.

Research Assistant: Psychophysiology Laboratory

Sept 1997-June 1998 Ohio University, Athens, Ohio

Assisted with research, funded by the American Heart Association, investigating the relationship between hypertension and pain sensitivity. Coordinated the lab, conducted participant recruitment and screening, organized data, scheduled appointments and made reminder calls.

Laboratory Director: Christopher France, Ph.D. 
Independent Contractor: Psycholegal Systems

Oct 1997-Feb 1998 Athens, Ohio

Interviewed, via telephone, residents of Clinton County, Ohio regarding their opinions on the judicial system and their knowledge of alleged facts on a pending court case in their county which had received considerable local and national pre-trial publicity.

Supervisor: Jack Arbuthnot, Ph.D.

Research Assistant: Social Psychology Laboratory

Jan 1997- June 1997

Ohio University, Athens, Ohio

Trained in the experimental study of the "genius effect." Conducted experimental sessions, as both a researcher and a confederate, with study participants.

Laboratory Director: Mark Alicke, Ph.D.

Research Assistant: Headache Laboratory

Sept 1996-June 1997

\section{Ohio University, Athens, Ohio}

Trained in the experimental study of tension headaches. Conducted telephone screening interviews and scheduled participants. Also responsible for executing treatment variables in the double-blind study and organizing and entering data.

Laboratory Director: Kenneth Holroyd, Ph.D.

\section{CLINICAL EXPERIENCE}

Graduate Student Therapist Quin Curtis Center, Department of Psychology

August 2001- Present West Virginia University, Morgantown, WV

Conducting individual therapy sessions with self-referred outpatient adult clients, as well as child clients and their parents. Conducting intake evaluations, assessments, case conceptualization, treatment, and treatment monitoring. Preparing intake, assessment, and termination reports.

Supervisor: Martin L. Boone, Ph.D.

Graduate Student Therapist

Quin Curtis Center, Department of Psychology

January 2001-Aug 2001

West Virginia University, Morgantown, WV

Conducted individual therapy sessions with self-referred outpatient child clients and their parents.

Conducted intake evaluations, case conceptualization, treatment, and treatment monitoring. Prepared intake, assessment, and termination reports.

Supervisor: Lindsey L. Cohen, Ph.D.

\section{Graduate Student Therapist}

Quin Curtis Center, Department of Psychology

July 2000-Present

\section{West Virginia University, Morgantown, WV}

Organized and aided in the development, running, evaluation, etc. of both a diabetes education group and a multidisciplinary chronic pelvic pain functional restoration group. Prepared and conducted group sessions, maintained progress notes, participated in supervision and staffing sessions to discuss group format, organization, maintenance, client progress, and treatment.

Supervisor: Jeannie Sperry, Ph.D. 
Graduate Student Therapist

Quin Curtis Center, Department of Psychology

August 1999-July 2000 West Virginia University, Morgantown, WV

Conducted individual therapy sessions with self-referred outpatient adult clients. Conducted intake evaluations, case conceptualization, treatment, and treatment monitoring. Prepared intake, assessment, and termination reports. Participated in weekly group supervision meetings to discuss client progress and treatment. Organized and participated in the development and implementation of a diabetes education group. Prepared and conducted group sessions, participated in supervision and staffing sessions. Organized and aided in the development of both a diabetes education group and a multidisciplinary chronic pelvic pain functional restoration group. Prepared and conducted group sessions, maintained progress notes, participated in supervision and staffing sessions to discuss group format, organization, maintenance, client progress, and treatment.

Supervisor: Jeannie Sperry, Ph.D.

Crisis Interventionist Counselor: Careline

Tri-County Mental Health and Counseling Center, Athens, Ohio

June 1997-June 1999

Providing supportive counseling by telephone to individuals in crisis via client-centered and brief therapy techniques. Contacting appropriate professionals and offering appropriate referrals. Maintaining accurate documentation of calls.

Supervisor: Mark Sutton, MSW.

250 hours

\section{TEACHING EXPERIENCE}

Course Co-Instructor: Health Psychology

Aug 2001- Dec 2001

Department of Psychology

West Virginia University, Morgantown, WV

Co-instructed 18 undergraduate students along with two other graduate students. Presented lectures on material necessary for examinations and course papers, constructed and graded course examinations, supervised testing sessions, and monitored student progress.

Supervisors: Kevin T. Larkin, Ph.D.

Graduate Teaching Assistant: Introduction to Clinical Psychology

Aug 2000-Dec 2000

Department of Psychology

West Virginia University, Morgantown, WV

Held two hour weekly dyad sessions with 2 to 3 first year clinical graduate students. Practiced basic interviewing skills and techniques via role-playing. Provided immediate feedback to the students and biweekly feedback regarding the students' progress to the course supervisor during bi-weekly meetings. Supervisor: Barry Edelstein, Ph.D.

Invited Graduate Student Panel Member: Seminar on Teaching Psychology September 2000 Department of Psychology West Virginia University, Morgantown, WV

Answered questions and discussed issues related to teaching an introductory undergraduate psychology course with approximately 12 first-time graduate student teaching assistants.

Supervisor: Kevin T. Larkin, Ph.D.

Course Instructor: Introduction to Psychology

Aug 1999-May 2000

Department of Psychology

West Virginia University, Morgantown, WV

Instructed 60 undergraduate students in 4 lecture sections ( 2 sections per semester). Presented lectures on material necessary for weekly quizzes, conducted weekly review sessions, supervised testing sessions, and monitored student progress.

Supervisors: Christina Adams, Ph.D., Connie Toffle, Ph.D., \& Joseph Scotti, Ph.D. 


\section{INTERNSHIP EXPERIENCE}

Intern: Office of the Ohio Public Defender

March 1998-June 1998 Athens County Branch, Athens, Ohio

Conducted initial interviews of clients preparing for a pre-trial hearing. Presented and discussed findings, notes, etc. concerning the case with the Public Defender.

Supervisor: Daniel Fries, J.D.

\section{WORK EXPERIENCE}

Summer Student Employee

Summer $2000 \& 2001$

\section{NIOSH, Office of the Director, Agricultural \& Immunotoxicology Division} Morgantown, WV

Responsible for organizing and maintaining various office files, including payroll and other financial documents. Utilized communication skills as well as various office equipment and computer hardware and software programs. Involved in a review of child injury prevention and prevention efforts on farms as well as with a project to examine and increase the utilization and dissemination of the North American Guidelines for Children's Agricultural Tasks (NAGCAT). Supervisor: Stephen Olenchock, Ph.D.

\section{Resident Coordinator: Wellspring Retreat and Resource Center}

June 1997-May 1999 Albany, Ohio

Responsible for the care and physical and emotional well-being of clients (ex-cult members and abuse victims). Maintaining accurate progress notes of the clients' activities, eating habits, mood, etc. Supervisor: Paul R. Martin, Ph.D.

Office Assistant: Honors Tutorial College

Sept 1995-Dec 1998 Ohio University, Athens, Ohio

Utilized communication skills and various office equipment. Responsible for processing Honors Tutorial College applications, as well as mailings, typing, filing, and training of other assistants.

Supervisor: Joseph Berman, Ph.D.

\section{Precollege Student Advisor: Honors Tutorial College $\quad$ Summer 1998} Ohio University, Athens, Ohio

Assisted with testing, registration, and orientation of incoming Honors Tutorial College students and parents. Supervisor: Joseph Berman, Ph.D.

Office Assistant: Department of Human Services Summer $1995 \& 1996$

Belmont County Branch, St. Clairsville, Ohio

Utilized communication skills and various office equipment. Responsible for typing, filing, and entering data.

Supervisor: Michael Kinter

\section{COMMITTEES}

\section{Adult Clinical Student Representative: Adult Clinical Training Committee $\quad$ Sep 2001 - Present} West Virginia University, Morgantown, WV

Attended bi-weekly meetings with department of psychology faculty and student representatives to discuss training issues and concerns. Will be co-organizing and overseeing interview weekend activities for potential graduate students in the spring semester. 
Adult Clinical Student Representative: Full Faculty Committee

Sep 2000 - May 2001

West Virginia University, Morgantown, WV

Attended bi-weekly meetings with department of psychology faculty and student representatives to discuss departmental issues and concerns.

Student Representative: Research Apprenticeship Program Proposal Review Committee February 1999 Ohio University, Athens, Ohio

Reviewed and ranked program proposals according to their overall merit, research value, and value as a learning experience for the student. Participated in committee meeting to discuss and finalize decisions regarding which proposals would receive funding for the following year.

Program Coordinator: Belinda Redden

\title{
PROFESSIONAL AFFILIATIONS
}

Student Affiliate:

\author{
American Psychological Association \\ Division 2, Society for the Teaching of Psychology \\ Division 12, Clinical Psychology \\ Division 38, Health Psychology \\ American Psychological Society \\ American Psychosomatic Society \\ Association for the Advancement of Behavior Therapy \\ Ohio Psychological Association \\ Society of Behavioral Medicine \\ West Virginia Psychological Association
}

\section{EDITORIAL EXPERIENCE}

\section{Student Ad Hoc Editorial Reviewer with:}

\author{
Kevin T. Larkin, Ph.D. \\ Health Psychology \\ May 2000 \\ Lindsey L. Cohen, Ph.D. \\ October 2000 \\ Journal of Pediatric Psychology \\ Lindsey L. Cohen, Ph.D. \\ October 2000 \\ Children's Health Care \\ Second Review \\ March 2001 \\ Lindsey L. Cohen, Ph.D. \\ April 2001 \\ Children's Health Care
}

\section{PUBLICATIONS}

Labus, J.S, France, C.R., \& Taylor, B.K. (2000). Vasovagal reactions in volunteer blood donors: Analyzingthe predictive power of the Medical Fears Survey. International Journal of Behavioral Medicine.

Bonk, V. A., France, C. R., \& Taylor, B. K. (2001). Distraction reduces vasovagal reactions to blood donation in novice donors with a blunting coping style. Psychosomatic Medicine. 
Zvolensky, M. J., Goodie, J. L., Ruggiero, K. J., Black, A. L., Larkin, K. T., \& Taylor, B. K. (in press). Perceived stress and anxiety sensitivity in the prediction of anxiety-related responding: A multichallenge evaluation. Anxiety, Stress, and Coping: An International Journal.

\section{PUBLISHED ABSTRACTS}

Bonk, V.A., France, C.R., \& Taylor, B.K. (1999). Interventions to reduce negative reactions experienced at blood donation. Annals of Behavioral Medicine, 21, S226.

\section{CONFERENCE PRESENTATIONS}

Black, A.L., Taylor, B.K., Goodie, J.L., Larkin, K., Schauss, S., \& Elnicki, M. (2001, March). Relation between ambulatory blood pressure and mood state. Poster presented at the annual meeting of the American Psychosomatic Society, Monterey, CA.

Goodie, J. L., Larkin, K. T., Taylor, B. K., Siegwarth, N., \& White, D. (2001, March). An examination of the transfer of heart rate feedback training to reduce heart rate response to laboratory tasks. Poster presented at the annual meeting of the American Psychosomatic Society in Monteray, CA.

Williams, K.A., Larkin, K., Kolar, M.M., Taylor, B.K., \& Plotka, A. (2001, March). Predictors of improvement in psychosocial factors in patients with coronary artery disease after participation in the mindfulnessbased stress reduction program. Poster presented at the annual meeting of the American Psychosomatic Society, Monterey, CA.

Goodie, J.L., Zvolensky, M.J., Ruggiero, K.J., Black, A.L., Larkin, K.T., \& Taylor, B.K. (2000, November). Predictors of Emotional Reactivity to Laboratory Challenges. Poster presented at the annual convention of the Association for the Advancement of Behavior Therapy, New Orleans, LA.

Taylor, B.K., France, C.R., \& Labus, J.S. (1999, June). The Medical Fears Survey predicts vasovagal reactions in volunteer blood donors. Poster presented at the annual convention of the American Psychological Society, Denver, CO.

\section{REFERENCES}

Kevin T. Larkin, Ph.D., Director of Clinical Training Associate Professor, Dept of Psychology West Virginia University Morgantown, WV 26506

(304) 293-2001 x668

Christina Adams, Ph.D.

Assistant Professor, Dept of Psychology

West Virginia University

Athens, Ohio 45701

(304) 293-2001 x672
Jeannie Sperry, Ph.D., Quin Curtis Center Director Dept of Psychology West Virginia University Morgantown, WV 26506

(304) 293-2001 x669

Lindsey L. Cohen, Ph.D. Assistant Professor, Dept of Psychology

West Virginia University Athens, Ohio 45701

(304) 293-2001 x644 